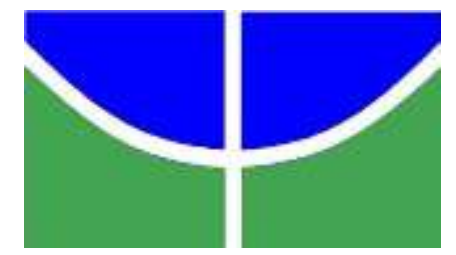

Universidade de Brasília

Instituto de Ciências Biológicas

Programa de Pós-Graduação em Ecologia

\title{
Semeadura direta de ervas, arbustos e árvores para restauração do Cerrado
}

Monique Alves

Brasília

Novembro de 2016 


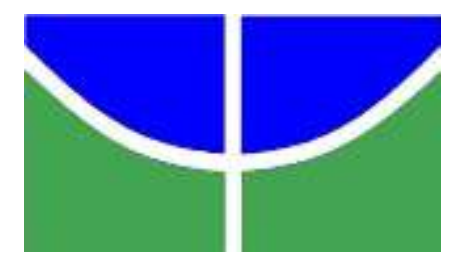

Universidade de Brasília

Instituto de Ciências Biológicas

Programa de Pós-Graduação em Ecologia

\title{
Semeadura direta de ervas, arbustos e árvores para restauração do Cerrado
}

\author{
Monique Alves \\ Orientador Dr. Daniel Luis Mascia Vieira \\ Dissertação submetida ao Departamento \\ de Ecologia do Instituto de Ciências \\ Biológicas da Universidade de Brasília, \\ como requisito parcial do Programa de \\ Pós-Graduação em Ecologia, para \\ obtenção do título de Mestre em Ecologia.
}

Brasília, DF

2016 
Universidade De Brasília

Instituto de Ciências Biológicas

Programa de Pós-Graduação em Ecologia

Monique Alves

\section{Semeadura direta de ervas, arbustos e árvores para restauração do Cerrado}

Banca Examinadora:

Dr. Daniel Luis Mascia Vieira

Presidente / Orientador

Embrapa - Cenargen

Dra. Cassia Beatriz Rodrigues Munhoz

Avaliador externo

PPGBOT - UnB
Dra. Heloisa Sinatora Miranda

Avaliador interno

PPGECL - UnB

Dra. Isabel Belloni Schimidt

Suplente

PPGECL - UnB 


\section{Agradecimentos}

Agradeço ao Daniel, por toda atenção, paciência e compreensão nesse período de orientação, pelas ideias sempre acompanhadas de empolgação e, por essa oportunidade, que me trouxe tantos aprendizados e encontros especiais. À Isabel, Xandão e Keiko, que também me permitiram participar desse projeto inspirador, e estiveram presentes auxiliando durante todo o processo, aprendi muito com vocês! Agradeço também por nosso abrigo em Alto Paraíso.

À todas as pessoas que compartilharam as aventuras nos campos e nas planilhas: Clau, Ana Carla, Fabi, Gabi, Bel, André, Gege, Grazi, Forga, Camis, Lesma, Manolito, Silvia, Alessandro, Marina, Rosana, Thauany, Bia, Letícia, João, Pablo, Leandro, Rafael, Vinícius, Vivi, Romina, Fernanda, Lana, Laura, Marília, Gustavo, Marcão e todos os outros do Restaura Cerrado. Agradeço especialmente Mardônio e Dudu, que além de dirigir, foram sempre super animados. Todos vocês me ajudaram a tornar esses dias mais leves e cheios de risadas.

Aos meus pais, Araci e Luiz, que desde sempre acreditaram e confiaram em mim e, mesmo com saudades, me apoiaram em todas as decisões. Vocês foram fundamentais para eu que pudesse estar aqui hoje. Agradeço a minha vó, pelo exemplo de força e

coragem. A energia das suas orações sempre me acompanha. À todos os familiares que puderam compartilhar carinho à distância No, Elen, Ju, Ve e Thiaguinho.

Obrigada Max, Letícia e Babi por todo socorro estatístico, discussões e revisões. E junto com esses, aos outros companheiros de alegria, gliter, bambolê e conversas transcendentais da minha querida Tapera: Parça, Gustavo, Marina e Rafa. Foi lindo demais estar com vocês!

Às amizades mais acolhedoras que pude ter, Laura, Forga, Ana Carla, Gabi e Roq, vocês são anjinhos que me fazem mais forte a cada dia e me ajudam a encontrar beleza nos desafios e descobertas.

Ao Aelton, Pâmela e Gisele, companheiros de EMBRAPA que sempre tiveram boas informações a acrescentar.

Obrigada professoras Cássia, Heloisa e Isabel, por aceitarem participar da banca. 
Agradeço a CAPES pela bolsa concedida, e ao ICMBio pela licença.

Agradeço a todos que encontrei, que deram graça a todos os momentos, e à todas as dificuldades que também me trouxeram grandes aprendizados, que vão muito além da ecologia. Agradeço por ter completado mais esse ciclo! 


\section{Resumo}

O Cerrado, bioma reconhecido por sua formação savânica, tem sido intensamente convertido em áreas de agricultura e pastagem, ameaçando a conservação da biodiversidade nesses ambientes. Por conta disso, se faz necessário o uso de métodos de restauração de recomposição da vegetação, iniciando ou acelerando a trajetória de um estado degradado a um estado de maior complexidade estrutural e maior diversidade, principalmente em locais ameaçados pela invasão de gramíneas exóticas. A inclusão de espécies competidoras que cresçam rápido e ocupem o solo pode constituir uma boa maneira de ultrapassar este gargalo. Neste trabalho foram conduzidos dois experimentos para (i) testar o estabelecimento de diferentes densidades de Stylosanthes capitata e Stylosanthes macrocephala no desenvolvimento de uma comunidade estabelecida por semeadura direta ao longo de 27 meses; e (ii) avaliar por 12 meses a dinâmica de comunidade com diferentes composições e estrutura iniciais, em áreas de restauração ecológica por semeadura direta em cerrado sentido restrito. O primeiro experimento foi baseado no plantio de 23 espécies em sete faixas de semeadura de $10 \times 100 \mathrm{~m}$, com três tratamentos de diferentes densidades de semeadura de Stylosanthes capitata $e$ Stylosanthes macrocephala. Foram feitas avaliações de densidade de indivíduos e cobertura do solo aos 8, 14 e 27 meses. Para o segundo experimento, em 2015 foi feita a avaliação de três áreas semeadas em 2012, 2013 e 2014, a partir do método de interepctação de pontos, com parcelas distribuídas de forma a abranger o maior gradiente de cobertura de espécies nativas plantadas e gramíneas africanas invasoras. A porcentagem de cobertura do solo foi estimada visualmente. Aos 27 meses havia $28 \%$ de solo exposto, $28 \%$ de espécies nativas semeadas e $39 \%$ de gramíneas exóticas. A densidade final de espécies foi de 13 espécies.5m-2 ${ }^{2}$ e de indivíduos foi de 154 indivíduos $\mathrm{m}^{-2}$ e 24 indivíduos $5 \mathrm{~m}^{-2}$ para respectivamente Stylosanthes capitata e Stylosanthes macrocephala. A composição das espécies variou, com as espécies herbáceas apresentando a maior densidade aos 27 meses (70 indivíduos $/ 5 \mathrm{~m}^{2}$ ) e as arbóreas as menores densidades (32 indivíduos $/ 5 \mathrm{~m}^{2}$ ). Parcelas com cobertura total inicial baixa (menos de 150 toques) apresentaram maior alteração da comunidade ao longo do tempo, e parcelas com cobertura total inicial alta (mais de 150 toques) variaram menos, indicando que uma alta cobertura inicial promove uma redução do espaço disponível para o crescimento das plantas, limitando, consequentemente, o aumento da cobertura e o estabelecimento de novas espécies. Em $64 \%$ das parcelas houve aumento na cobertura relativa de espécies exóticas, enquanto 34\% apresentou aumento na cobertura relativa de espécies nativas. $O$ melhor ajuste à regressão sigmoidal demonstra que a competição é assimétrica, A NMDS mostra que houve alteração da comunidade de um ano para o outro. A semeadura direta é uma boa técnica para introdução de espécies de todos os estratos de formações de Cerrado. Para isso, é necessário um controle mais eficiente das espécies exóticas, assim como a introdução de espécies de gramíneas nativas com características funcionais similares às exóticas invasoras.

Palavras chave: semeadura direta, efeito de prioridade, estrato herbáceo, estrato arbustivo. 


\section{Abstract}

The Cerrado, Biome recognized for its savanna formation, has been intensively converted into crops and pasture areas, which threatens the region's biodiversity conservation. In this context, it is necessary to deploy vegetation restoration methods, which start or accelerate the trajectory of a degraded area to a state of greater structural complexity and diversity, especially in places threatened by invasion of exotic grasses. The inclusion of competing species that grow and cover the ground quickly can be a good way to overcome this obstacle. In this study, two experiments were carried out to (i) to test different establishment densities of Stylosanthes capitata e Stylosanthes macrocephala in the development of a community introduced by direct sowing, by observing the establishment and development of the sown community over 27 months; and (ii) assess during 12 months the dynamics of the community with different initial compositions and structure in strict sense cerrado areas restored by direct seeding. The first experiment was based on the planting of 23 species in seven sowing strips of $10 \times 100-m$, with three treatments of different sowing densities of Stylosanthes capitata e Stylosanthes macrocephala. Density assesments were made at $8^{\text {th }}, 14^{\text {th }}$ and $27^{\text {th }}$ months. In the second experiment, in 2015 were made assesments of three areas sown in 2012, 2013 e 2014, in plots distributed in order to cover the greater coverage gradient of native planted species and invasive African grasses. Soil cover was estimated visually. At the $27^{\text {th }}$ month, there were $28 \%$ of soil exposed, $28 \%$ of native species, and $39 \%$ of exotic grasses. The final density of species was 13 species $/ 5 \mathrm{~m}^{2}$, of individuals was 154 individuals $/ 5 \mathrm{~m}^{2}$, and 24 individuals $/ 5 \mathrm{~m}^{2}$ for respectively Stylosanthes capitata e Stylosanthes macrocephala. Species composition varied, with herbaceous plants presenting the highest final density at the $27^{\text {th }}$ month $\left(70\right.$ individuals $\left./ 5 \mathrm{~m}^{2}\right)$ and trees the smallest densities (32 individuals $/ 5 \mathrm{~m}^{2}$ ). Plots with total initial cover below 150 touches showed the greatest change in the community over time, and plots with more than 150 touches at the initial stage varied less, indicating that high initial coverage promotes a reduction of the space available for plant growth, limiting consequently, the increase in coverage and the establishment of new species. In $64 \%$ of the plots, there was an increase in the relative cover of exotic species, while $34 \%$ showed an increase in the relative cover of native species. The best fit to the sigmoidal regression demonstrated that competition is asymmetric. The NMDS ordination showed that the community changed from one year to the next. Direct sowing is a good technique to introduce 
species from all strata of Cerrado formations. A more efficient control of exotic species previously introduced for pasture is therefore required.

Keywords: direct sowing, priority effect, herbaceous stratum, shrub stratum. 


\section{Sumário}

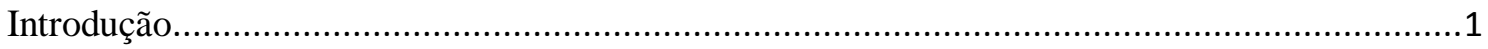

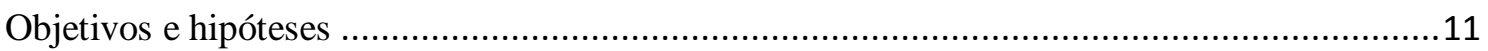

Material e métodos............................................................................... 12

Área de estudo ................................................................................................ 12

1. Experimento com três densidades de semeadura de Stylosanthes capitata e Stylosanthes

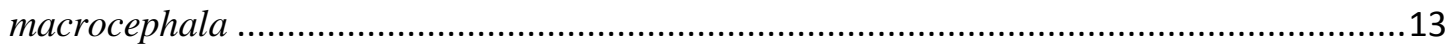

2. Experimento Dinâmica de comunidades com diferentes composições iniciais ..............18

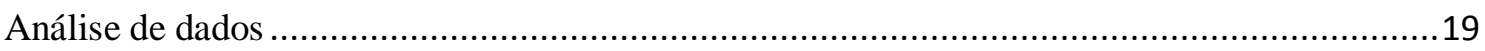

1. Experimento com três densidades de semeadura de Stylosanthes Stylosanthes capitata e

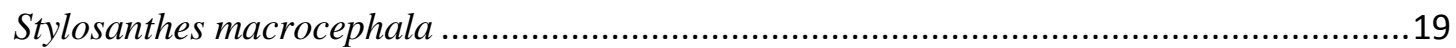

2. Experimento Dinâmica de comunidades com diferentes composições iniciais .............20

Resultados .21

1. Experimento Três densidades de Stylosanthes capitata e Stylosanthes macrocephala...21

2. Experimento Dinâmica de comunidades com diferentes composições iniciais ................28

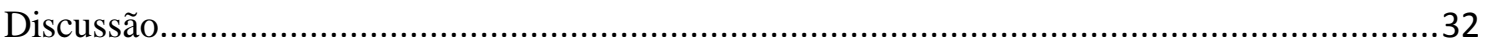

Implicações para a prática .................................................................................. 41

Referências bibliográficas Não estão padronizadas. ................................................4 41 


\section{Lista de figuras e tabelas}

Figura 1. Relações hipotéticas esperadas entre a cobertura de nativas e exóticas no tempo inicial e final.

Figura 2. a. Localização das faixas de semeadura $(10 \mathrm{~m} \times 100 \mathrm{~m})$ do experimento com três densidades de Stylosanthes capitata e Stylosanthes macrocephala na área de estudo no parque Nacional da Chapada dos Veadeiros-GO, e b. esquema de parcelas $(10 \mathrm{~m} \times 33 \mathrm{~m})$ e subparcelas $(1 \mathrm{~m} \times 1 \mathrm{~m})$.

Figura 3. a. Preparo do solo, b. semeadura a lanço, c. sementes separadas para a semeadura, d, e, f. área de semeadura aos 8, 14 e 27 meses (consecutivamente), g. unidade amostral experimento densidades de Stylosanthes capitata e Stylosanthes macrocephala, h, i. amostragem experimento dinâmica de comunidades com diferentes composições iniciais. j. parcela com espécies nativas diversas e solo exposto, k. parcela com muito capim nativo, 1. espécies nativas em conjunto com gramíneas exóticas, m. parcela dominada por gramínea exótica, n. parcela após a retirada de gramíneas exóticas, o. diversidade de espécies nativas, 6 meses após a semeadura.

Figura 4. Mudanças na porcentagem de cobertura das formas de crescimento (a) nativas semeadas, (b) gramíneas exóticas, (c) nativas não semeadas e (d) solo exposto, aos 8, 14 e 27 meses após a semeadura, nos tratamentos baixa, média e alta densidade de Stylosanthes capitata e Stylosanthes macrocephala. Barras são médias \pm erro padrão. Letras iguais indicam ausência de diferença entre médias, e N.S. indica que não houve diferença significativa entre os tratamentos e entre os anos, testadas com o teste a posterior de Tukey HSD, $\mathrm{P} \leq 0,05$. Ausente $=0$ gramas de Stylosanthes por parcela, média=20 g/parcela, alta=40 g/parcela de $10 \times 33 \mathrm{~m}^{2} \ldots \ldots .23$

Figura 5. Mudanças ao longo do tempo na (a) densidade de espécies nativas plantadas em $5 \mathrm{~m}^{2}$, (b) densidade total de indivíduos de espécies nativas plantadas em $5 \mathrm{~m}^{2}$ e (c) densidade de indivíduos de Stylosanthes capitata e Stylosanthes macrocephala em $5 \mathrm{~m}^{2}$, aos 8, 14 e 27 meses após a semeadura. Barras são médias \pm erro padrão. Letras iguais indicam ausência de diferença entre médias, e N.S. indica que não houve diferença significativa entre os tratamentos e entre os anos, testadas pelo teste a posterior de Tukey HSD, $\mathrm{p} \leq 0,05$. Ausente $=0$ gramas de Stylosanthes por parcela, média $=20 \mathrm{~g} /$ parcela, alta $=40 \mathrm{~g} /$ parcela de $10 \times 33 \mathrm{~m}^{2}$. .25

Figura 6. Ordenação escalonamento multidimensional não métrico (NMDS) mostrando o efeito do tempo na composição da comunidade baseado na composição e abundância de espécies (índice de similaridade de Bray-Curtis; stress 0.2419). Números representam parcelas, vermelho $=8$ meses, azul $=14$ meses, verde $=27$ meses. Tratamento baixa densidade: $1,2,3,4,5$, 6, 7; média: 8, 9, 10,11, 12, 13, 14; alta: 15, 16, 17, 18, 19, 20, 21.

Figura 7. Densidade de indivíduos por espécie em $5 \mathrm{~m}^{2}$, aos 8, 14 e 27 meses após a semeadura, nas classes arbustivas, herbáceas e arbóreas. Barras pretas representam espécies arbustivas, barras cinza representam espécies herbáceas e barras brancas espécies arbóreas (para abreviação das espécies, ver Tabela 1).

Figura 8. Cobertura relativa (\%) de espécies nativas/exóticas, por parcela de $1 \mathrm{~m}^{2}$. Cobertura total (considerada como número total de toques). Círculos representam valores no tempo inicial (2015) e setas representam valores das parcelas no tempo final (2016). Linhas vermelhas indicam direção de redução de espécies nativas com o tempo, consequência do aumento de exóticas, e linhas azuis indicam aumento de espécies nativas e redução conjunta de exóticas...29 
Figura 9. Regressão logística entre a. cobertura relativa de espécies nativas no tempo inicial e final e b. cobertura relativa de espécies nativas no tempo inicial e final.

Figura 10. Escalonamento multidimensional não-métrico (NMDS) ordenando as parcelas com base na composição e abundância das espécies nativas e exóticas no tempo inicial (2015) e final (2016) (índice de similaridade de Bray-Curtis; stress 0.313);

Figura 11. a. regressão entre eixo 1 da NMDS no tempo inicial, e delta da parcela no eixo 1 , para parcelas com baixa densidade (menos que 388 toques); b. regressão entre eixo 1 da NMDS no tempo inicial, e delta da parcela no eixo 1, para parcelas com alta densidade (mais que 388 toques); c. regressão entre eixo 2 da NMDS no tempo inicial, e delta da parcela no eixo 2 , para parcelas com baixa densidade (menos que 388 toques); d. regressão entre eixo 2 da NMDS no tempo inicial, e delta da parcela no eixo 2, para parcelas com alta densidade (mais que 388 toques)

Tabela 1. Espécies semeadas em experimento no Parque Nacional da Chapada dos Veadeiros PNCV, separadas por hábito de crescimento, quantidade de sementes por metro quadrado, peso de 100 sementes e forma de beneficiamento ( $\mathrm{tg} g=$ máquina trituradora de grama). *Componentes da variedade campo grande, avaliados em conjunto. **Densidade variável de acordo com o tratamento (baixa $=0 \mathrm{~g} /$ parcela, média $=20 \mathrm{~g} /$ parcela, alta=40 g/parcela de $10 \times 33$ $\left.\mathrm{m}^{2}\right)$.

Tabela 2. Espécies semeadas nos experimentos de semeadura direta nos anos de 2012, 1013 e 2014, nos hábitos de vida arbustos, ervas e árvores, em área de Restauração no Parque Nacional da Chapada dos Veadeiros (PNCV). .53 


\section{Introdução}

\section{Ecologia e conservação do Cerrado}

O Cerrado é considerado o maior e mais diverso ecossistema savânico do mundo. Entretanto, grande parte da sua área tem sido convertida em agricultura e pastagem (Diniz-filho et al., 2009; Klink e Machado, 2005). A intensificação dessas atividades e a existência de poucas áreas protegidas ameaçam a conservação da biodiversidade (Silva et al., 2006), do solo e da água nesse bioma (MMA, 2015). Todavia, pouca atenção tem sido dada à rápida perda de ecossistemas não florestais no Brasil e, para evitar o avanço dessa perda, políticas de conservação e sustentabilidade devem ser adequadas às necessidades desses ambientes (Overbeck et al., 2015).

O plantio de espécies arbóreas é a estratégia mais usada para recuperação de áreas degradadas (Chazdon, 2008). No Cerrado também a maioria dos trabalhos que visam restaurar áreas degradadas usam somente espécies arbóreas ou espécies de gramíneas exóticas (Carbone et al., 2001; Silva, 2006). Entretanto, para restaurar biomas graminosos, como campos e savanas, tais formas de vida são elementos de grande importância, pois são as responsáveis por cobrir todo o solo (Klink e Moreira, 2002). Portanto, é necessário desenvolver métodos que incluam ervas e arbustos (Parr et al., 2014; Veldman et al., 2015).

O bioma Cerrado é composto por diversas fitofisionomias, que abrangem desde campos abertos a florestas densas. A vegetação nessas fitofisionomias é composta pelos estratos arbóreo/arbustivo e subarbustivo/herbáceo (Eiten, 1972). Em áreas conservadas de fitofisionomias campestres, o estrato rasteiro, que inclui ervas e arbustos, pode representar mais de 90\% da cobertura vegetal (Ribeiro and Walter, 2008). Em cerrado sentido restrito, o estrato rasteiro, que inclui espécies herbáceas a arbustivas, abrange até $56 \%$ das espécies, e representa $28 \%$ da biomassa acima do solo. Das 12.000 espécies 
da vegetação nativa conhecida, mais de 300 são gramíneas nativas, e a relação de espécies não arbóreas e arbóreas é de 5,6:1 (Mendonça et al., 2008).

Na região do Cerrado, há duas estações bem definidas, caracterizadas por chuvas concentradas e seca, que influenciam a vegetação (Ribeiro and Walter, 1998), principalmente com relação à floração e frutificação (Lenza and Klink, 2006). O fogo é uma característica comum, principalmente nas fitofisionomias que apresentam o estrato herbáceo mais desenvolvido. Há uma alta produção de biomassa graminosa durante a estação úmida, que posteriormente seca e favorece a propagação de queimadas. O regime, principalmente, a frequência do fogo podem afetar o ciclo de crescimento das plantas, e muitas espécies apresentam adaptações que lhes confere resistência ao fogo, como casca espessa e órgãos subterrâneos extensos, como rizomas e xilopódios (Miranda et al., 2009). A presença de gramíneas exóticas, altamente produtivas, estabelece uma retroalimentação positiva com a frequência e a intensidade do fogo, tornando-se um problema para conservação e restauração de formações campestres, savânicas e florestais do bioma (Pivello and Coutinho, 1996). Outros fatores determinantes na distribuição da vegetação desse bioma são a umidade e fertilidade do solo. Os solos do Cerrado são, em sua maioria, bem drenados e profundos, ácidos, com baixas concentrações de Cálcio e Magnésio e altos níveis de saturação de Alumínio. As plantas nativas geralmente possuem adaptações às limitações do solo, com relação à umidade, temperatura, baixos níveis de nutrientes e altos níveis de alumínio, sendo que diversas espécies são tolerantes e acumulam Alumínio nos tecidos das folhas e raízes (Haridasan, 1982). Apesar da limitação da germinação de sementes no Cerrado, diversas espécies de gramíneas (Aires et al. 2013), arbustos e árvores (Salazar 2011) apresentam sementes viáveis e longevas, quando enterradas no solo (Zaidan and Carreira, 2008). Essa limitação em áreas campestres pode ser superada, entre outros métodos, por meio 
da semeadura direta, que permite a introdução em larga escala de sementes em áreas a serem restauradas, usando maquinários agrícolas adaptáveis (Martins, 2015).

\section{Espécies exóticas invasoras no Cerrado}

Gramíneas Africanas foram trazidas para o Brasil para forragem para bovinos, mas hoje estão presentes em muitos fragmentos de Cerrado, dominando manchas do ambiente, se expandindo em alcance e abundância e competindo com herbáceas (Klink, 2009; Pivello et al., 1999), arbustos e árvores nativos (Brandt e Seabloom, 2012; Seabloom et al., 2006). A disseminação dessas gramíneas invasoras é favorecida pela intensa fragmentação, que transforma a vegetação natural de Cerrado em fragmentos cercados por pastagens e culturas agrícolas (Pivello et al., 1999). A dominância por gramíneas exóticas que foram plantadas ou colonizaram áreas de agricultura abandonada é um dos fatores mais limitantes ao estabelecimento e desenvolvimento de espécies nativas (Aide, 2000; Holl, 1999), e podem representar uma ameaça permanente para a restauração do Cerrado, uma vez que formações abertas nesse bioma apresentam de 10 a 60\% de cobertura por espécies arbóreas e arbustivas (Ratter et al., 1997), permitindo entrada de luz suficiente para a manutenção das gramíneas exóticas (Pivello et al., 2007).

\section{Espécies invasoras e seus efeitos nas comunidades e ecossistemas}

A invasão por exóticas pode modificar o funcionamento de ecossistemas, por provocar alterações na representação de grupos funcionais (Mason e French, 2008). Espécies de gramíneas Africanas invasoras que se estabelecem em ambientes abertos de Cerrado são, em sua maioria, variedades comerciais resultantes de melhoramento genético, para aumento de produtividade e sobrevivência nas condições do Cerrado 
Brasileiro. Por isso, apresentam características que conferem superioridade competitiva sobre as nativas, tendo, geralmente, maior habilidade relacionada à aquisição e retenção de recursos (Tecco et al., 2010), usando-os mais eficientemente do que as nativas, até mesmo em ambientes com baixa disponibilidade desses recursos (Funk, 2013). Essas espécies de gramíneas Africanas invasoras que se estabelecem em ambientes abertos de Cerrado comumente possuem metabolismo $\mathrm{C} 4$, tornando-as adaptadas à alta entrada de luminosidade. Além disso, elas possuem ampla capacidade de dispersão por reprodução vegetativa e sexuada, são altamente eficientes na fotossíntese e utilização de nutrientes, têm altas taxas de crescimento, são tolerantes à herbivoria, ciclo reprodutivo rápido, produzem muitas sementes, formam banco de sementes denso e persistente, e apresentam alta capacidade de germinação. Tais caraterísticas conferem superioridade competitiva por recursos como água, radiação solar, nutrientes e ocupação de espaço, quando comparadas às nativas, incluindo as gramíneas, que têm grande importância e abundância nesses ambientes de Cerrado (Freitas e Pivello, 2005). Além disso, muitas gramíneas exóticas possuem sistemas radiculares densos, que inibem a aquisição de água e nutrientes pelas nativas, e a biomassa produzida acima do solo pode impedir a germinação e estabelecimento de espécies nativas (D’Antonio, 1992).

\section{Espécies invasoras e os efeitos de prioridade}

Diferenças sutis na ordem de chegada de espécies podem causar diferenças consideráveis na estrutura e função das comunidades, que podem ser ampliadas ao longo do tempo e espaço através do crescimento populacional e interações bióticas, e é chamado de efeito de prioridade (Fukami, 2015). Tal efeito pode ser inibitório, se a espécie que chega antes afeta de forma negativa a próxima espécie que chega, ou então 
facilitativo, se a espécie que se estabelece primeiro interfere de forma positiva no estabelecimento da espécie que chega posteriormente (Fukami, 2015).

A competição nos estágios iniciais de desenvolvimento, associada a pequenas diferenças no tamanho inicial e crescimento entre plantas vizinhas pode ter efeitos nas interações competitivas a longo prazo (Funk, 2013; Mangla et al., 2011; Suding e Goldberg, 1999). Espécies exóticas podem crescer mais rápido que nativas e exercer efeito de prioridade, tendo vantagens na absorção de recursos antes das nativas, ou iniciar rapidamente o crescimento após um pulso de fornecimento de recurso, por exemplo, após uma chuva, tornando-os indisponíveis às nativas ("preenchimento de recursos"; Verdú e Traveset, 2005). Além disso, espécies invasoras possuem atributos correlacionados ao seu desempenho que são competitivamente mais vantajosos do que os atributos das espécies nativas, resultando em uma maior capacidade de explorar, adquirir e reter recursos quando comparado às nativas (Daehler, 2003; Kleunen, 2010; Matzek, 2012). Em vegetações campestres com diferentes composições, plantas exóticas introduzidas apresentam abundância reduzida se já houver espécies do mesmo grupo funcional que elas, como leguminosas, arbustivas e gramíneas C3 e C4 (Fargione et al., 2003; Fukami, 2015).

O esgotamento de recursos pode dificultar a colonização por espécies tardias com necessidades de recursos equivalentes aos das espécies que se estabelecem inicialmente (Fargione et al., 2003; Fukami et al., 2005). A ordem de chegada das espécies a um local irá influenciar as interações futuras entre elas, resultando do preenchimento de nichos ou sua modificação. O efeito de prioridade exercido pelas exóticas pode causar aumento da sua biomassa e da disponibilidade de sementes (Schwinning e Weiner, 1998), aumentando sua dominância em comunidades campestres de plantas (Abraham et al., 2009). Plantas maiores, com maior cobertura e biomassa, 
competem assimetricamente, pois absorvem uma proporção maior dos recursos disponíveis (Schwinning e Weiner, 1998). Assim, a presença de espécies exóticas dominantes pode ser prejudicial às nativas que, produzindo plantas menores e menos sementes, terão desvantagem competitiva (Wilson, 1988), podendo resultar na extinção local de nativas (Stevens e Fehmi, 2011). Entretanto, espécies exóticas também podem sofrer efeito de prioridade exercido por espécies nativas. Em vegetação campestre, gramíneas exóticas são suprimidas em até $85 \%$ quando nativas germinam cinco semanas antes, e somente $8 \%$ quando germinam simultaneamente, e a germinação das nativas antes das exóticas pode beneficiar seu crescimento e acelerar a restauração de campos (Grman e Suding, 2010), sendo que as gramíneas nativas crescem mais a cada ano após o plantio, se tornam mais resistentes e suprimem as exóticas (Corbin e D’Antonio, 2004; Dyer e Rice, 1999).

Dickson et al. (2012), em vegetações campestres, encontraram efeito de prioridade mais acentuado em espécies invasoras do que em espécies nativas, sendo que as invasoras, quando semeadas primeiro, apresentaram biomassa média de 97,5\%, e as nativas quando semeadas primeiro apresentaram biomassa de 29,8\%. Young et. al (2014) testaram a competição entre gramíneas exóticas e espécies nativas em campos temperados na Califórnia, considerando o tempo relativo de chegada das sementes pela manipulação da competição entre espécies de gramíneas nativas e exóticas anuais, e constataram que o controle de gramíneas exóticas antes da semeadura e a rápida cobertura do solo por nativas resultaram em redução das exóticas e aumento das nativas (Young et al., 2015). Também em uma comunidade campestre, em Buenos Aires, a adição de sementes de espécies nativas e a remoção de espécies exóticas invasoras, em conjunto, também promoveram o aumento da cobertura de espécies nativas após dois anos (Tognetti e Chaneton 2012). Outros estudos incluem a semeadura de gramíneas e 
arbustos nativos para a restauração de campos, demonstrando que podem ser bons competidores com gramíneas exóticas (Emery, 2007; Fargione et al., 2003; Kimball et al., 2014; Seabloom et al., 2003; Sheley e Half, 2006).

\section{Restauração ecológica e similaridade de atributos}

Além da competição com espécies invasoras, outros fatores, como a limitação de sementes, no estabelecimento e das características de microsítios, comprometem o recrutamento de espécies nativas e a recuperação de ecossistemas campestres (Bakker e Berendse, 1999; Calviño-Cancela, 2007; Clark et al., 1998; Eriksson e Erlhén, 1992; Foster et al., 2007; Muller-Landau et al., 2002). A chegada de sementes depende da densidade e fecundidade de indivíduos adultos, da capacidade de dispersão e da distância que as sementes podem atingir (Clark et al., 1998). O número de espécies nativas no banco de sementes e de gemas, em campos, diminui de acordo com a intensidade de manejo, aumentando a ocupação por espécies ruderais e exóticas (Favreto et al., 2005) e reduzindo a capacidade de recuperação da vegetação campestre original (Andrade et al., 2015). A limitação de recrutamento, ou estabelecimento, depende da sobrevivência e germinação da semente e da sobrevivência da plântula (Clark et al., 1998), e são etapas críticas na formação da comunidade (Fenner, 2000) e fundamentais na restauração de ecossistemas (Lima et al., 2014). Tais etapas são influenciadas por condições físicas, como luminosidade, temperatura, textura do solo e disponibilidade de água e nutrientes (Calviño-Cancela, 2007; Falk et al., 2006; Holl et al., 2000). A heterogeneidade de tais fatores divide o habitat em um mosaico de microsítios (Grubb, 1977) e podem também limitar o sucesso do estabelecimento das plântulas (Calviño-Cancela, 2007; Falk et al., 2006; Khan, 2013). Em ambientes onde o solo foi alterado por conta do manejo, e posteriormente abandonado, as baixas taxas de 
colonização podem ocorrer devido a limitações de micrositio relacionadas a alterações nas características físicas do solo (Murphy et al., 2004) e de recursos disponíveis. (Foster et al., 2007). A luminosidade é um dos principais fatores que controla a dormência e germinação de sementes em campo, sendo decisivo também para a sobrevivência de plântulas (Ferraz et al., 2001). A temperatura influencia a porcentagem e velocidade da germinação, por interferir na embebição e nos processos metabólicos das sementes (Castro e Hilhorst 2004).

A restauração ecológica constitui "atividade intencional que inicia ou acelera a recuperação de um ecossistema, em relação à sua saúde, integridade e sustentabilidade" (SER, 2004). Envolve ações que reduzem as limitações à regeneração natural da comunidade, manipulando condições ecológicas para proporcionar o estabelecimento ou o vigor de espécies-chave, que irão colaborar com a restauração de processos ecológicos (Prober et al., 2005). Essas ações devem levar em consideração as limitações decorrentes do estado de degradação, e os fatores culturais do local, que interfiram na conformação final do estado desejado (Aronson et al., 2007). As limitações de microsítio podem ser superadas com o preparo do solo, revolvendo o solo com grade aradora (Martins, 2015) para eliminar a gramínea exótica e descompactar o solo (Hobbes e Norton, 1996). Após esse preparo, métodos como o plantio de mudas, transferência do banco de sementes (Sampaio et al., 2007), transferência de feno (Kiehl et al., 2010; Stradic et al., 2014) e a semeadura direta (Campos-Filho et al., 2013; Silva et al., 2015) suprem a limitação de sementes e estabelecimento. Na semeadura direta devem ser usadas sementes viáveis e profundidade de semeadura adequada, prevenindo a dessecação de sementes, com o uso de palhada e plantas de cobertura e reduzindo a exposição a altas temperaturas em áreas abertas, e a incidência de patógenos e 
herbívoros. Além disso, a germinação pode ser acelerada com o uso de técnicas que quebrem a dormência (Silva et al., 2015).

O controle de gramíneas exóticas invasoras antes da semeadura é uma condição necessária para a restauração, pois elas são fortes competidoras (Celis e Jose, 2011; Durigan et al., 2013; Grman e Suding, 2010; Hoffmann e Haridasan, 2008). Um dos meios mais eficientes de prevenir a dominância de gramíneas exóticas é o estabelecimento de cobertura por gramíneas nativas (Young et al., 2015).

Estabelecer comunidades de plantas que sejam resistentes à invasão por espécies exóticas ainda é uma dificuldade para a restauração ecológica (Funk et al., 2008). O aumento da diversidade de espécies e de funções em comunidades de plantas nativas pode aumentar a resistência à invasão (Roberts et al., 2010), por ter uma maior captura dos recursos, eliminando ou reduzindo nichos vazios para invasoras (Fargione et al., 2003; Tilman, 1999). Espécies invasoras têm menor probabilidade de estabelecimento e colonização em comunidades com espécies nativas que possuem atributos semelhantes, e que são funcionalmente similares, e em comunidades onde os nichos já estão ocupados (Emery, 2007; Fargione et al., 2003; Funk et al., 2008; Young et al., 2009, 2005). Assim, para ter sucesso na restauração devemos selecionar espécies nativas com atributos similares aos das espécies invasoras, incluindo uma diversidade de atributos funcionais (Funk et al., 2008). Foi constatado que comunidades campestres, na Califórnia, que continham a espécie nativa Elymus glaucus, funcionalmente similar à invasora Centaurea solstitialis, foram mais resistentes à invasão (Young et al., 2009). Outros estudos em vegetações campestres observaram que em comunidades com menor riqueza de espécies nativas, consequentemente com menor diversidade funcional, que não tinham atributos similares à espécie invasora, foram menos resistentes à invasão, implicando em redução da biomassa das espécies nativas. Esse fato pode ser explicado 
pelo uso mais completo de recursos em comunidades mais ricas (Zavaleta e Hulvey, 2004). A restauração baseada no preparo do solo contribui para a manutenção da diversidade da comunidade de plantas e redução de espécies exóticas invasoras, pois a alta riqueza em escala local pode promover a utilização mais completa dos recursos disponíveis (Liao et al., 2015), e limitar assim o uso desses recursos pelas exóticas, também porque a maior vantagem de dias de estabelecimento resulta em um efeito de prioridade mais forte para as nativas (Von Gillhaussen et al., 2014).

Para incluir espécies arbustivas e herbáceas na restauração, o método mais comum é a semeadura direta. Esse método tem se mostrado eficaz na restauração da composição de espécies arbustivas, arbóreas (Engel Parrotta, 2001; Knight et al., 1998) e herbáceas (Bakker et al., 2003; Foster et al., 2007). Espécies herbáceas crescem rapidamente, podendo controlar a erosão e melhorar as condições físicas, químicas e biológicas do solo (Silva e Corrêa, 2010). Além disso, espécies arbóreas e arbustivas, quando semeadas, desenvolvem sistemas radiculares resistentes e profundos que as ajudam a se estabelecer (Corr, 2003). A semeadura direta pode ser feita distribuindo sementes em área total ou em linhas e covas. A semeadura em área total é preferível, pois pode promover o enriquecimento e o adensamento florístico (Martins, 2015), enquanto a semeadura em linhas ou em covas não proporciona essa cobertura do solo em áreas de Cerrado, e dificilmente resultará em redução significativa da cobertura do solo por gramíneas exóticas.

É necessário saber qual é a densidade ideal de semeadura de espécies herbáceas que propicie boa cobertura do solo a ponto de resistir à invasão de espécies exóticas invasoras, mas possibilitando a coexistência dos três estratos e a maximização da diversidade. $\mathrm{O}$ uso de altas taxas de sementes na semeadura pode contribuir com o controle de espécies indesejáveis introduzidas (Wilson, 2002). Para o Cerrado, há 
poucos trabalhos sobre restauração, sendo a maioria com espécies arbóreas. Foram encontrados trabalhos em áreas de mineração no Cerrado, utilizando Stylosanthes capitata e Stylosanthes macrocephala, nos quais as operações para a implantação do Stylosanthes capitata e Stylosanthes macrocephala e o seu desenvolvimento melhoraram física, química e biologicamente o substrato minerado, além de favorecer o aumento da diversidade e redução da dominância por espécies exóticas (Silva e Corrêa, 2008, 2010; Starr et al., 2013). O gênero Stylosanthes possui sistema radicular robusto e alta capacidade de colonizar solos de baixa fertilidade, se associando a bactérias fixadoras de nitrogênio (EMBRAPA, 1993)

\section{Objetivos e hipóteses}

1. Testar os efeitos de diferentes densidades de indivíduos de Stylosanthes capitata e Stylosanthes macrocephala provenientes da semeadura, no desenvolvimento de uma comunidade estabelecida por semeadura direta ao longo de 27 meses.

Testei a hipótese que a cobertura formada por Stylosanthes capitata e Stylosanthes macrocephala reduz a reocupação por espécies de gramíneas exóticas invasoras, favorecendo o estabelecimento das espécies nativas plantadas. Porém, é possível que haja uma cobertura ótima de Stylosanthes capitata e Stylosanthes macrocephala para maximizar a cobertura e diversidade de espécies nativas e reduzir a reocupação de gramíneas exóticas invasoras.

2. Avaliar, por 12 meses a dinâmica da comunidade com diferentes composições e estrutura iniciais, desde dominadas por gramíneas invasoras, dominadas por ervas nativas, e todo o gradiente de composição intermediária, em áreas de restauração ecológica por semeadura direta em cerrado sentido restrito. 
Testei as hipóteses que (i) a ocupação do solo por espécies nativas plantadas reduz a ocupação de espécies de gramíneas exóticas invasoras; (ii) áreas com ocupação por gramíneas exóticas tenderão a ter dominância na cobertura por exóticas, no futuro, pela maior eficiência competitiva (Figura 1) e (iii) áreas com menor porcentagem de cobertura total (solo exposto) tenderão a ter aumento na cobertura por espécies exóticas, também pela maior eficiência competitiva.

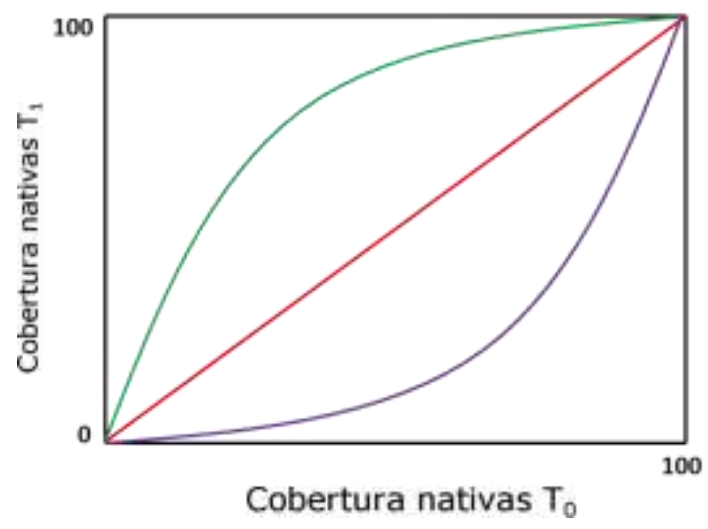

Figura 1. Relações hipotéticas esperadas entre a cobertura de nativas e exóticas no tempo inicial e final.

\section{Material e métodos}

\section{Área de estudo}

Os experimentos foram conduzidos no Parque Nacional da Chapada dos Veadeiros (PNCV), no município de Alto Paraíso de Goiás - GO $\left(14^{\circ} 04^{\prime} 45^{\prime \prime} \mathrm{S}\right.$ e 47³7'57" W). O PNCV é uma unidade de conservação federal de proteção integral, que foi criada pelo Decreto 49.875, de 11 de janeiro de 1961. Está localizado a $260 \mathrm{~km}$ de Brasília-DF e compreende os municípios de Alto Paraíso, Cavalcante, Terezina de Goiás e Colinas do Sul, totalizando 65.515 hectares (ICMBio, 2009).

A região da Chapada dos Veadeiros apresenta regime de Clima Tropical, subúmido, do tipo AW na classificação de Köppen, com verão chuvoso e inverno seco. A 
precipitação média anual é de 1.625 mm (ICMBio, 2009) e a temperatura média anual máxima na região é de $28,5^{\circ} \mathrm{C}$ e a mínima de $18^{\circ} \mathrm{C}$ (Goiás, 2006). Insere-se no Complexo Montanhoso Veadeiros-Araí, com altitude de 800 a 1.650 m. O relevo predominante é de planalto forte ondulado, montanhoso e escarpado (Felfili, 2007) e os solos são, em geral, rasos e pedregosos com maior ocorrência de cambissolos, solos litólicos e latossolos vermelho-amarelo (Haridasan, 2007). Nas parcelas de estudo, o relevo é plano e solo é do tipo plintossolo, variando de pouco a bem drenado.

A vegetação original da área foi convertida em agricultura e posteriormente em pastagem, e está abandonada há aproximadamente 20 anos. A vegetação original era cerrado sentido restrito, caracterizado por um estrato graminoso contínuo, com estrato arbóreo e arbustivo variando de 10 a 60\%. As áreas de semeadura estão a 500 metros de remanescentes de vegetação original. As espécies de gramíneas exóticas introduzidas para cultivo da pastagem dominavam completamente a área antes da intervenção de restauração. As principais espécies são Urochloa decumbens (Stapf) R.D. Webster, Urochloa brizantha (Hochst. ex A. Rich.) R.D. Webster e Urochloa humidicola (Rendle) Morrone \& Zuloaga (capim braquiária), Andropogon gayanus Kunth. (capim andropogon), Hyparrhenia rufa (Nees) Stapf (capim jaraguá), e Melinis minutiflora P. Beauv (capim gordura).

\section{Experimento com três densidades de semeadura de Stylosanthes capitata}

\section{e Stylosanthes macrocephala}

A partir de experimentos anteriores de plantio para restauração, foram selecionadas 23 espécies nativas da região, sendo 11 árvores, oito gramíneas, dois arbustos, dois subarbustos e uma palmeira (Tabela 1). As sementes e frutos foram coletados em áreas do PNCV e em remanescentes de vegetação nativa nos arredores do 
Parque. As coletas foram entre maio e setembro de 2012 e as sementes foram beneficiadas (nenhuma semente recebeu tratamento para quebra de dormência) e armazenadas em sacos de ráfia em temperatura ambiente.

Foram feitas sete faixas de semeadura de $10 \times 100 \mathrm{~m}$, afastadas no mínimo $10 \mathrm{e}$ no máximo 380 metros (Figura 2). Em cada faixa de semeadura foram semeadas as 23 espécies em três tratamentos de diferentes densidades de indivíduos de Stylosanthes capitata e Stylosanthes macrocephala, baseada na densidade de sementes no momento da semeadura (ausente $=0 \mathrm{~g}$, média $=20 \mathrm{~g}$ e alta $=40 \mathrm{~g}$ ), em parcelas contíguas de $10 \times 33$ m, totalizando sete blocos de três parcelas.

Em junho de 2012 toda a área foi roçada com roçadeira acoplada em trator, e em setembro o solo foi preparado com grade aradora tracionada por trator em três passadas sequenciais. A gradagem eliminou a cobertura de capins exóticos e nivelou o solo moderadamente, restando torrões (Figura 3a). Exceto a gradagem, nenhum método pré ou pós-emergente de controle para os capins exóticos foi utilizado.

Em novembro de 2012, as 23 espécies foram semeadas em densidades variáveis entre si de acordo com a disponibilidade de sementes, respeitando a mesma densidade por espécie em todas as parcelas (Tabela1, Figura 3b). Uma das espécies consideradas foi um mistura comercial de Stylosanthes capitata e Stylosanthes macrocephala (variedade campo grande), leguminosas nativas do bioma Cerrado com boa capacidade de cobrir o solo, foi semeada em três densidades, em conjunto com as 22 espécies nativas dos estratos herbáceo, arbustivo e arbóreo. As sementes foram distribuídas manualmente a lanço em área total, espécie a espécie, cobrindo de forma homogênea a área das faixas de semeadura delimitadas. Os frutos de Dypteryx alata e sementes de Syagrus romanzoffiana e Magonia pubescens foram enterrados logo abaixo da 
superfície, para que fossem incorporados facilmente ao solo. As demais espécies foram semeadas sobre a superfície do solo.

Para contagem de plântulas para obter a densidade de indivíduos e de espécies plantadas e avaliação da cobertura do solo, em cada parcela foram feitas cinco subparcelas de $1 \mathrm{~m}^{2}$ distantes cinco metros entre si, organizadas em um transecto diagonal na parcela, delimitado a cada amostragem (Figura 2). As sub-parcelas foram amostradas com um quadro de $1 \times 1 \mathrm{~m}$. A densidade de indivíduos e de espécies foi obtida pela contagem de indivíduos e identificação das espécies. A porcentagem de cobertura do solo foi estimada visualmente, com precisão de $1 \%$, de acordo com a porcentagem nas seguintes formas de crescimento: espécies nativas semeadas, gramíneas exóticas, espécies nativas não semeadas (árvores e arbustos e ervas presentes na área antes da semeadura e que rebrotaram após a gradagem, ou que chegaram naturalmente) e solo exposto. A amostragem foi realizada aos 8, 14 e 27 meses após a semeadura.

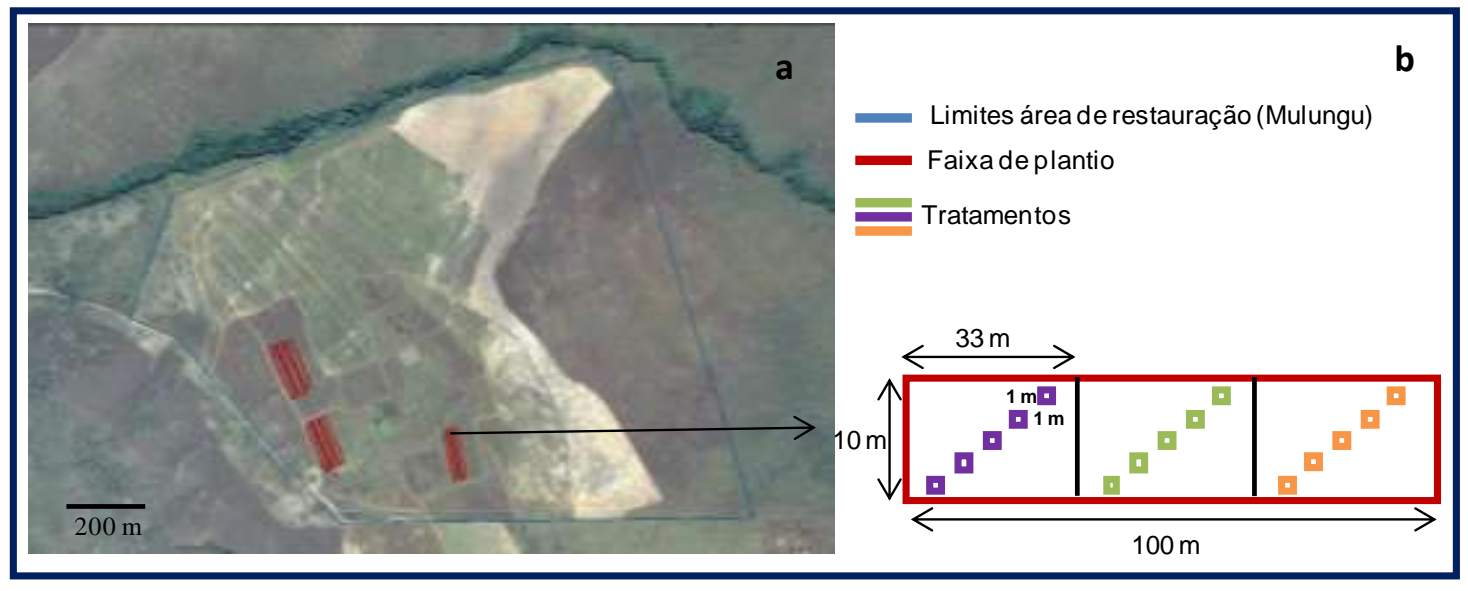

Figura 2. a. Localização das faixas de semeadura $(10 \mathrm{~m} \times 100 \mathrm{~m})$ do experimento com três densidades de Stylosanthes capitata e Stylosanthes macrocephala na área de estudo no parque Nacional da Chapada dos Veadeiros-GO, e b. esquema de parcelas $(10 \mathrm{~m} \times 33 \mathrm{~m})$ e sub-parcelas $(1 \mathrm{~m} \times 1 \mathrm{~m})$. 

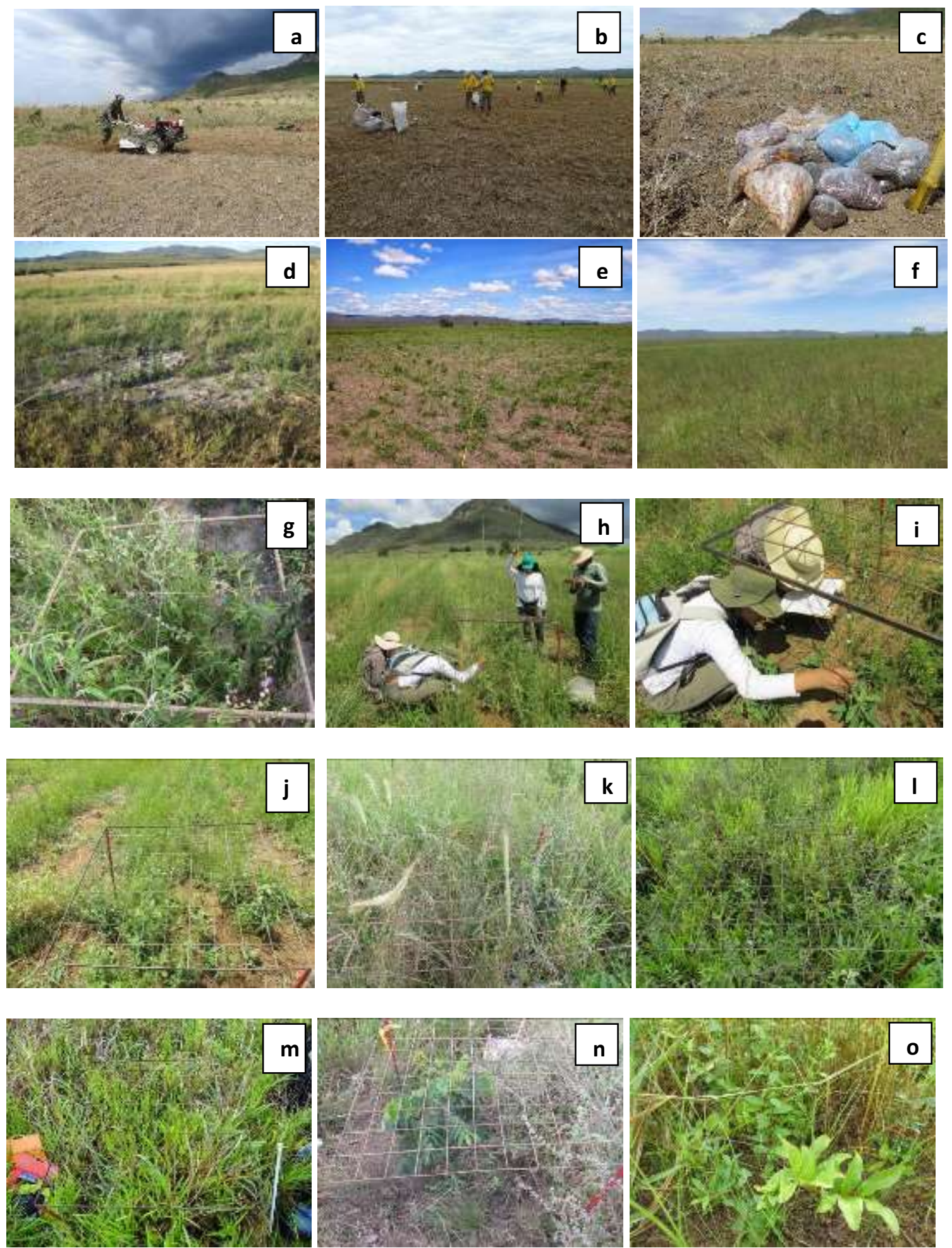

Figura 3. a. Preparo do solo, b. semeadura a lanço, c. sementes separadas para a semeadura, d, e, f. área de semeadura aos 8, 14 e 27 meses (consecutivamente), g. unidade amostral experimento densidades de Stylosanthes capitata e Stylosanthes macrocephala, h, i. amostragem experimento dinâmica de comunidades com diferentes composições iniciais. j. parcela com espécies nativas diversas e solo exposto, k. parcela com muito capim nativo, $\mathbf{l}$. espécies nativas em conjunto com gramíneas exóticas, m. parcela dominada por gramínea exótica, n. parcela após a retirada de gramíneas exóticas, o. diversidade de espécies nativas, 6 meses após a semeadura. 
Tabela 1. Espécies semeadas em experimento no Parque Nacional da Chapada dos Veadeiros - PNCV, separadas por hábito de crescimento, quantidade de sementes por metro quadrado, peso de 100 sementes e forma de beneficiamento ( $\mathrm{mtg}=$ máquina trituradora de grama). *Componentes da variedade campo grande, avaliados em conjunto. ${ }^{*}$ Densidade variável de acordo com o tratamento (ausente=0 g/parcela, média=20 g/parcela, alta=40 g/parcela de $10 \times 33 \mathrm{~m}{ }^{2}$ ).

\begin{tabular}{|c|c|c|c|c|c|c|}
\hline Nome Científico & Nome comum & Família & Sementes $(\mathrm{g}) / \mathrm{1m}^{2}$ & 100 sementes $(\mathrm{g})$ & Beneficiamento & Abreviação \\
\hline \multicolumn{7}{|l|}{ Arbustos } \\
\hline Lepidaploa aurea (Mart. ex DC.) H.Rob. & Amargoso & Asteraceae & 0,9 & $0.08 \pm 0.03$ & $\mathrm{mtg}$ & Lep. aur. \\
\hline $\begin{array}{l}\text { Vernonanthura Vernonanthura polyanthes (Sprengel) } \\
\text { Vega \& Dematteis }\end{array}$ & Assa peixe & Asteraceae & 0,225 & $0.03 \pm 0.00$ & $\mathrm{mtg}$ & Ver. ph \\
\hline \multicolumn{7}{|l|}{ Subarbusto } \\
\hline \multirow{2}{*}{\multicolumn{7}{|c|}{$\begin{array}{l}\text { Stylosanthes macrocephala M.B.Ferreira \& Sousa }\end{array}$}} \\
\hline & & & & & & \\
\hline \multicolumn{7}{|l|}{ Gramíneas } \\
\hline Aristida sp. 1 & Aristida & Poaceae & 0,173 & - & $\mathrm{mtg}$ & Ari.sp. \\
\hline Aristida sp. 2 & Aristida & Poaceae & 0,1 & - & $\mathrm{mtg}$ & Ari.sp. \\
\hline Axonopus aureus P. Beauv. & Pé de galinha & Poaceae & 0,08 & $0.06 \pm 0.01$ & peneira & Axo. aur. \\
\hline Echinolaena inflexa (Poir.) Chase & Capim flexinha & Poaceae & 0,1 & $0.22 \pm 0.04$ & peneira & Ech. inf. \\
\hline Loudetiopsis chrysothrix (Nees) Conert & Capim brinco de princesa & Poaceae & 0,325 & $0.47 \pm 0.05$ & $\mathrm{mtg}$ & Lou. chr. \\
\hline Trachypogon spicatus (L.f.) Kuntze & Capim fiapo & Poaceae & 0,875 & 0.24 & $\mathrm{mtg}$ & Tra. sp. \\
\hline Schizachyrium sanguineum (Retz.) Alston & Capim roxo & Poaceae & 0,005 & $0.19 \pm 0.05$ & mtg & Sch. san. \\
\hline \multicolumn{7}{|l|}{ Arbóreas } \\
\hline Buchenavia tomentosa Eichler & Mirindiba & Combretaceae & 0,3 & $95.21 \pm 0.61$ & Secagem ao sol & Buc. cap. \\
\hline Dipteryx alata Vogel & Baru & Fabaceae & 9 & $2259.06 \pm 48.47$ & nenhum & Dip. ala. \\
\hline Enterolobium contortisiliquum (Vell.) Morong & Tamboril & Fabaceae & 1,225 & $45.31 \pm 0.81$ & $\mathrm{mtg} /$ peneira & Ent. con. \\
\hline Eremanthus glomerulatus Less. & Candeia & Asteraceae & 1,25 & $0.40 \pm 0.19$ & peneira & Ere. glo. \\
\hline Hymenaea stigonocarpa Mart. ex Hayne & Jatobá & Fabaceae & 0,5 & $373.07 \pm 101.86$ & mtg/peneira & Hym. sti. \\
\hline Jacaranda brasiliana (Lam.) Pers. & Caroba & Bignoniaceae & 0,09 & $2.73 \pm 0.15$ & separação manual & Jac. bra. \\
\hline Magonia pubescens A. St. -Hil. & Tingui & Sapindaceae & 1,25 & $182.32 \pm 55.15$ & separação manual & Mag. pub. \\
\hline Myracrodruon urundeuva Allemão & Aroeira & Anacardiaceae & 0,34 & $1.94 \pm 1.68$ & peneira & Myr. uru. \\
\hline Plathymenia reticulata Benth. & Vinhático & Fabaceae & 0,125 & $4.50 \pm 0.06$ & peneira & Pla. ret. \\
\hline Solanum lycocarpum A. St. -Hil. & Lobeira & Solanaceae & 0,075 & $2.78 \pm 0.76$ & remoção da polpa & Sol. lyc. \\
\hline Tachigali vulgaris L.G.Silva \& H.C.Lima & Carvoeiro & Fabaceae & 6,1 & & remoção da polpa & Scl. pan. \\
\hline Terminalia argentea Mart. & Capitão & Combretaceae & 1,01 & $24.96 \pm 0.37$ & peneira & Ter. arg. \\
\hline Palmeira & & & & 1.33 & & \\
\hline Syagrus romanzoffiana (Cham.) Glassman & Gueroba & Arecaceae & 5 & $1.34 \quad 0,58(a)$ & nenhum & Sya. rho. \\
\hline
\end{tabular}




\section{Experimento Dinâmica de comunidades com diferentes composições iniciais}

Nos anos de 2012, 2013 e 2014, na mesma área de estudo em restauração no PNCV, foram realizados três diferentes experimentos de semeadura direta de espécies herbáceas, arbustivas e arbóreas nativas do Cerrado, havendo espécies diferentes em cada ano (Anexo 1). Esses experimentos tiveram como objetivo testar diferentes densidades e formas de preparo do solo para aprimoramento da técnica para a restauração de áreas degradadas de Cerrado. As diferentes idades, tratamentos experimentais, dinâmicas das interações entre plantas e variações de solo resultaram em manchas com diversas composições de espécies e biomassa total, ocorrendo manchas dominadas por capins exóticos, por arbustos nativos ou gramíneas nativas. Para avaliar o efeito da composição da comunidade inicial (tempo zero do estudo, mas com 1, 2 e 3 anos de semeadura) na composição após um ano, em janeiro de 2015 foram alocadas 92 parcelas de $1 \mathrm{~m}^{2}$, tendo parcelas estabelecidas nos plantios que foram realizados no ano de 2012, parcelas nos plantios realizados no ano de 2013 e parcelas nos plantios de 1024. Nessas parcelas, buscou-se abranger o maior gradiente possível de cobertura de espécies nativas plantadas e gramíneas africanas invasoras, com diversas composições de espécies e cobertura total, existindo desde parcelas com domínio de capins exóticos, arbustos nativos ou gramíneas nativas, assim como parcelas com uma combinação de espécies nativas e exóticas. Para obter parcelas onde havia total ausência de capins invasores, em abril do mesmo ano foram alocadas mais 30 parcelas, onde todos os indivíduos de gramíneas africanas foram retirados manualmente.

A cobertura das espécies nativas e exóticas foi obtida através do método de interceptação de pontos (ITT, 1996), buscando-se representar a ocupação do espaço por cada espécie. Para isso, a parcela foi delimitada por um quadro de ferro de $1 \mathrm{~m}^{2}$ 
subdividido em 100 quadrículas de $100 \mathrm{~cm}^{2}$, suspenso a uma altura de 1,20 m. No centro de cada quadrícula foi inserida uma vareta de bambu de $2 \mathrm{~m}$ de altura por $5 \mathrm{~mm}$ de diâmetro marcada a cada $10 \mathrm{~cm}$ de altura, e então contabilizado o número de toques de cada espécie, em cada faixa de altura. Este método amostra a cobertura por estrato e contabiliza todos os toques na vareta, permitindo uma cobertura do solo de mais de 100\%, consistindo numa razoável aproximação da amostragem de biomassa por método destrutivo. Para comparar estes dois métodos de amostragem foram escolhidas 15 parcelas que representassem o maior gradiente possível de cobertura de espécies nativas plantadas e gramíneas africanas invasoras, em que foi realizada uma dupla amostragem (por pontos e coleta de biomassa) para fins de comparações das estimativas de cobertura de cada grupo de espécies obtidas a partir destes dois métodos. A partir disto, houve correlação entre a cobertura obtida pelo método de interceptação de pontos e coleta de biomassa das espécies semeadas de arbustos $(r=0,53, p<0,05)$, arbóreas $(r=0,7, p<0,05)$, gramíneas $(r=0,67, p<0,05)$ e herbáceas (excluindo-se as gramíneas; $r=0,9, p<0,05)$ e também para as gramíneas exóticas $(\mathrm{r}=0,6, \mathrm{p}<0,05)$, indicando que a cobertura é representativa para biomassa. Essas correlações foram estimadas a partir de 15 parcelas, nas quais foram registradas a cobertura e posteriormente a biomassa, a partir da coleta da parte aérea, secagem em estufa a $70^{\circ} \mathrm{C}$ por 48 horas (Pérez-Harguindeguy et al., 2013) e medição da massa seca em balança de precisão.

\section{Análise de dados}

\section{Experimento com três densidades de semeadura de Stylosanthes Stylosanthes capitata e Stylosanthes macrocephala}

Para avaliar se houve alteração na estrutura e diversidade da comunidade ao longo dos anos e entre os tratamentos, foram avaliadas a porcentagem de cobertura do 
solo por forma de crescimento, densidade de espécies, densidade de indivíduos total e densidade de indivíduos de Stylosanthes capitata e Stylosanthes macrocephala. Para avaliar se houve diferença na porcentagem de cobertura, entre os três tratamentos e entre as amostragens, foi feita a análise de variância multivariada (MANOVA). Como o resultado da MANOVA foi significativo para o fator tempo, para verificar a diferença entre 8, 14 e 27 meses após a semeadura, foram feitas análises de variância (ANOVA) de medidas repetidas para a cobertura em cada forma de crescimento e para as densidades de indivíduos total e de Stylosanthes capitata e Stylosanthes macrocephala. Foram feitos testes a posteriori de Tukey HSD para comparações múltiplas entre pares de médias. Somente os dados de densidade de Stylosanthes capitata e Stylosanthes macrocephala não apresentaram distribuição normal, testada pelo teste de ShapiroWilk, e foram transformados pela raiz quadrada. A homocedasticidade foi confirmada pela análise gráfica dos resíduos das ANOVAS. Para resumir variações na composição e abundância de espécies nativas após 8, 14 e 27 meses da semeadura, foram comparadas graficamente as médias de densidade de indivíduos por espécie e feita análise de ordenação por escalonamento multidimensional não-métrico (NMDS) baseada na composição e densidade de espécies nativas nas parcelas. Foi usado o índice de dissimilaridade de Bray-Curtis como medida de distância, com 100 permutações. As análises e gráficos foram feitos no programa R (Team, 2014) e Statística 10.0 (StatSoft, Inc. 2011).

\section{Experimento Dinâmica de comunidades com diferentes composições iniciais}

Para observar a trajetória da comunidade de um ano para outro, foi feito um gráfico de vetores, sendo o eixo y valores de biomassa totais para as parcelas, e o eixo x, 
valores de porcentagem relativa de espécies nativas e exóticas em cada parcela no período estudado. O comprimento da seta indica a variação na biomassa da parcela no período estudado. Para testar se a alta cobertura inicial de exóticas resulta em alta cobertura final de exóticas, e se a alta cobertura inicial de nativas resulta em alta cobertura final de nativas, foram também feitas regressões entre a cobertura relativa no tempo inicial e final, com as classes "nativas" e "exóticas", com dados transformados pelo arcoseno da raiz quadrada. Para observar variações na estrutura e composição da comunidade no período de um ano, foi feita uma ordenação por escalonamento multidimensional não-métrico (NMDS), com base na composição e cobertura das espécies nativas e exóticas na comunidade, usando o índice de dissimilaridade de BrayCurtis como medida de distância, com 100 permutações. Os scores da NMDS no eixo 1 no tempo inicial foram correlacionados com a alteração dos scores no eixo 1 (t1-t0), para avaliar a direção da mudança das parcelas. As análises e gráficos foram feitos no programa R (Team, 2014), Statística 10.0 (StatSoft, Inc. 2011) e CurveExpert Professional 2.3 (Hyams, 2010).

\section{Resultados}

1. Experimento Três densidades de Stylosanthes capitata e Stylosanthes macrocephala

Oito meses após a semeadura, havia 20 espécies das 23 plantadas, e após 14 e 27 meses foram amostradas todas as espécies plantadas, exceto Mikania sp. Diferentemente do esperado, os tratamentos com diferentes densidades de indivíduos de Stylosanthes capitata e Stylosanthes macrocephala não promoveram diferenças na cobertura do solo por forma de crescimento $\left(\mathrm{F}_{(2,12)}=1,58, \mathrm{p}=0,15\right)$, diferindo somente entre os tempos de amostragem $\left(\mathrm{F}_{(2,12)}=6,92, \mathrm{p}<0,001\right)$. Entre os oito e os 27 meses após a semeadura, solo 
exposto diminuiu de 59 para $28 \% \quad\left(\mathrm{~F}_{(2,12)}=73,57, \mathrm{p}<0,001\right)$, nativas semeadas aumentaram de 9 para $28 \%\left(\mathrm{~F}_{(2,12)}=27,6, \mathrm{p}<0,001\right)$, gramíneas exóticas aumentaram de 28 para $39 \%\left(\mathrm{~F}_{(2,12)}=8,3, \mathrm{p}=0,001\right.$; embora o teste de Tukey não tenha mostrado diferenças estatísticas entre as datas) e nativas não plantadas mantiveram-se com cobertura inferior a 3,5\% (Figura 3). 


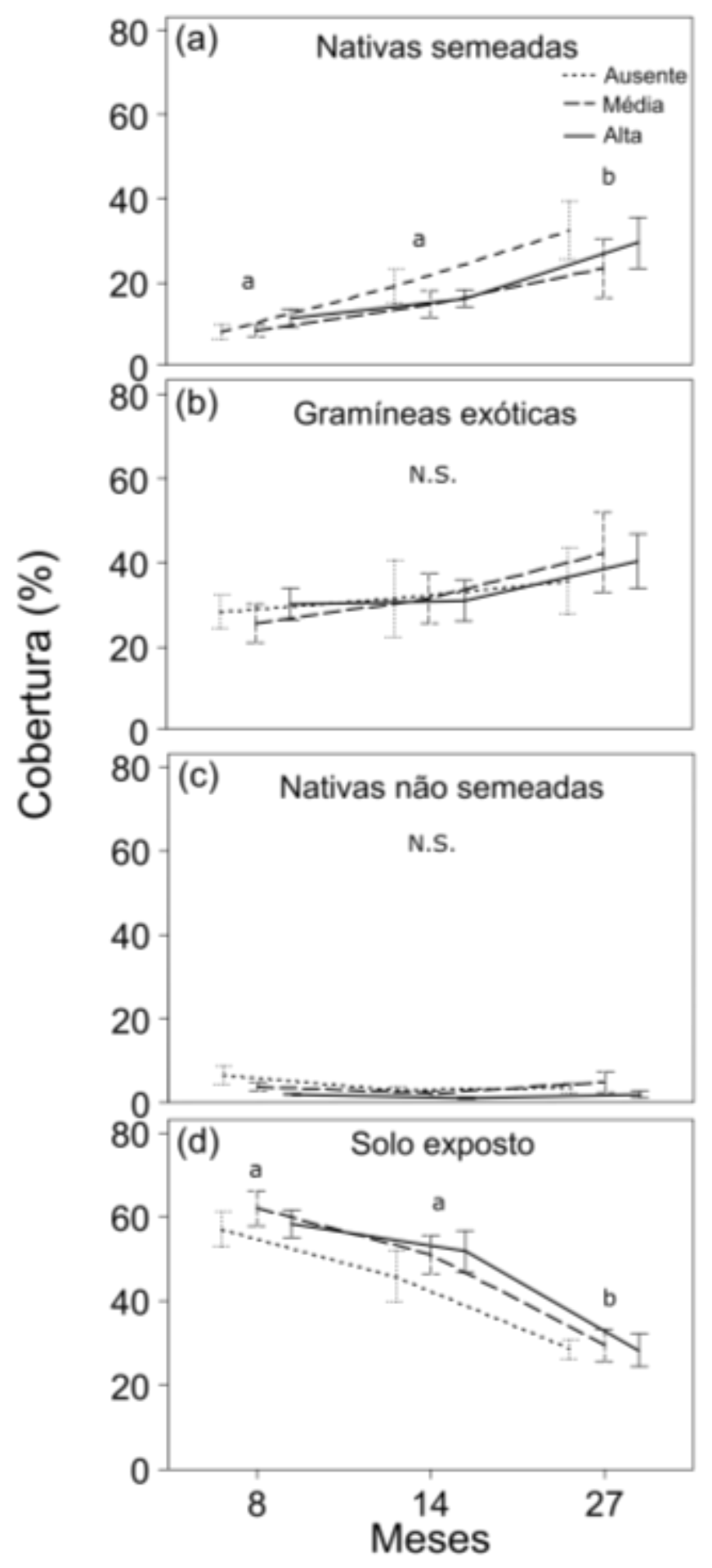

Figura 4. Mudanças na porcentagem de cobertura das formas de crescimento (a) nativas semeadas, (b) gramíneas exóticas, (c) nativas não semeadas e (d) solo exposto, aos 8, 14 e 27 meses após a semeadura, nos tratamentos baixa, média e alta densidade de Stylosanthes capitata e Stylosanthes macrocephala. Barras são médias \pm erro padrão. Letras iguais indicam ausência de diferença entre médias, e N.S. indica que não houve diferença significativa entre os tratamentos e entre os anos, testadas com o teste a posterior de Tukey HSD, $\mathrm{P} \leq 0,05$. Ausente $=0$ gramas de Stylosanthes por parcela, média $=20 \mathrm{~g} /$ parcela, alta= $40 \mathrm{~g} /$ parcela de $10 \times 33 \mathrm{~m}^{2}$. 
A semeadura em densidades diferentes de Stylosanthes capitata e Stylosanthes macrocephala resultou em diferentes densidades de plantas desta espécie nos três tratamentos após 8 meses e isto se manteve até os 27 meses após o plantio $\left(\mathrm{F}_{(2,18)}=7,95\right.$, $\mathrm{p}=0,001)$. Os tratamentos com diferentes densidades de Stylosanthes capitata e Stylosanthes macrocephala não promoveram diferenças na densidade de espécies $\left(\mathrm{F}_{(2,18)}=0,48, \mathrm{p}=0,63\right)$ e de indivíduos $\left(\mathrm{F}_{(2,18)}=2,0, \mathrm{p}=0,16\right)$ nativos plantados. Entre os oito e os 27 meses após a semeadura, a densidade de espécies nativas aumentou significativamente de 11 para 13 espécies. $5 \mathrm{~m}^{-2}$ (Figura 5; $\mathrm{F}_{(2,36)}=6.9, \mathrm{p}<0,001$ ). A densidade total de indivíduos não se alterou significativamente ao longo do estudo e alcançou 154 indivíduos/5 $\mathrm{m}^{2}$ aos 27 meses, incluindo Stylosanthes capitata e Stylosanthes macrocephala, e a densidade de Stylosanthes capitata e Stylosanthes macrocephala, somente, teve em média 24 indivíduos $/ 5 \mathrm{~m}^{2}$ aos 27 meses. 

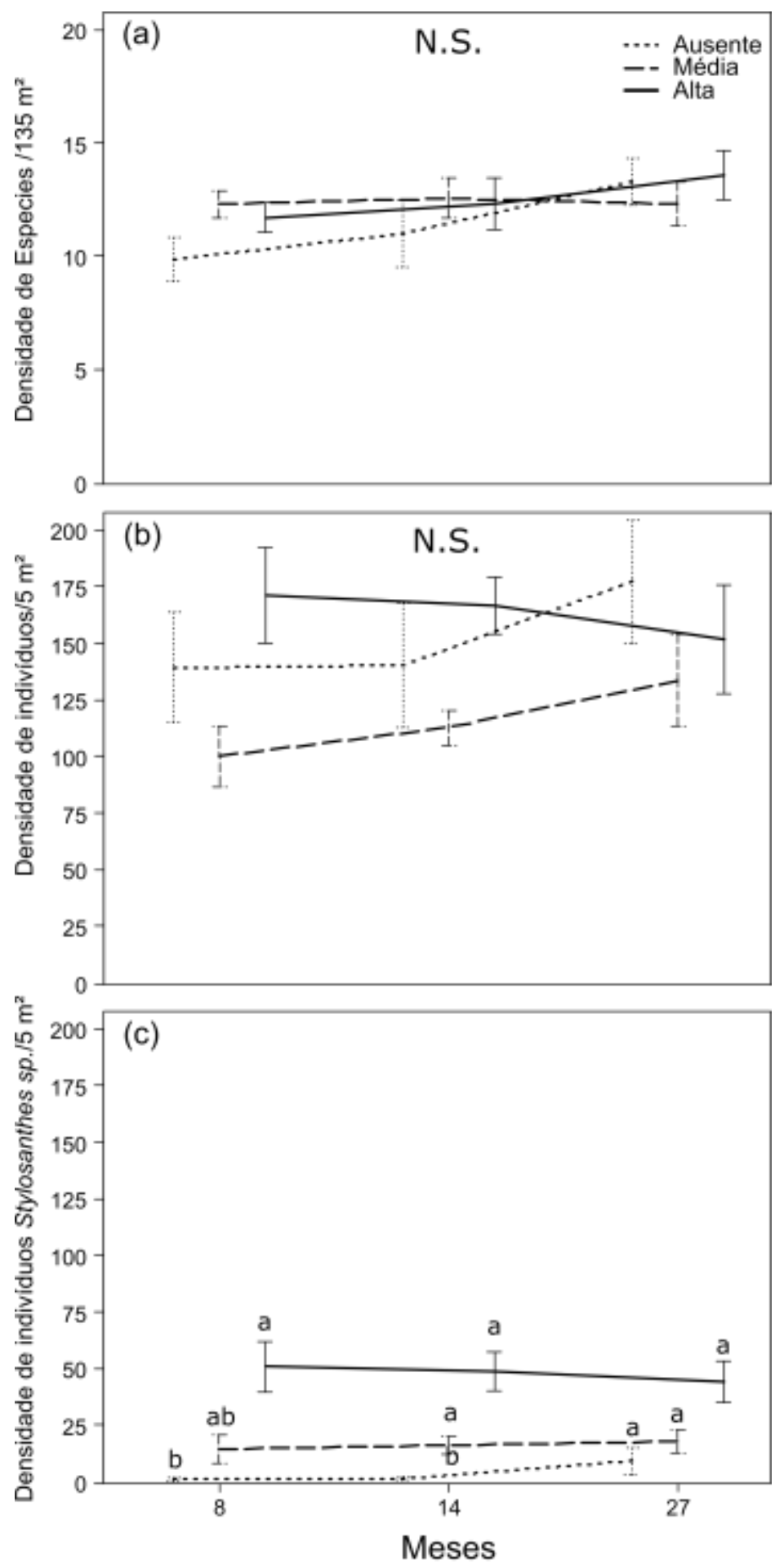

Figura 5. Mudanças ao longo do tempo na (a) densidade de espécies nativas plantadas em $5 \mathrm{~m}^{2}$, (b) densidade total de indivíduos de espécies nativas plantadas em $5 \mathrm{~m}^{2}$ e (c) densidade de indivíduos de Stylosanthes capitata e Stylosanthes macrocephala em $5 \mathrm{~m}^{2}$, aos 8, 14 e 27 meses após a semeadura. Barras são médias \pm erro padrão. Letras iguais indicam ausência de diferença entre médias, e N.S. indica que não houve diferença significativa entre os tratamentos e entre os anos, testadas pelo teste a posterior de Tukey HSD, $\mathrm{p} \leq 0,05$. Ausente $=0$ gramas de Stylosanthes por parcela, média $=20$ $\mathrm{g} /$ parcela, alta $=40 \mathrm{~g} /$ parcela de $10 \times 33 \mathrm{~m}^{2}$. 
A composição de espécies variou ao longo do estudo, evidenciada pela ordenação das parcelas ao longo do eixo 1 da NMDS, com as parcelas aos 8 meses com valores negativos e aos 14 e 27 com valores positivos (Figura 6). Houve uma alteração na ordenação das parcelas, influenciada especialmente pelas espécies de gramíneas nativas. As espécies de gramíneas nativas aumentaram em densidade relativa depois de 14 meses, similares às parcelas aos 27 meses (Figuras 6 e 7). As espécies arbustivas apresentaram a maior densidade de indivíduos nas duas primeiras amostragens e diminuíram aos 27 meses. As gramíneas nativas tiveram a maior densidade aos 27 meses (70 indivíduos $/ 5 \mathrm{~m}^{2}$ ). As espécies arbóreas tiveram as menores densidades (32 indivíduos $/ 5 \mathrm{~m}^{2}$ ) (Figura 7). Foi observada reprodução de indivíduos de seis espécies semeadas: Lepdaploa aurea, Stylosanthes capitata, Stylosanthes macrocephala, Vernonanthura, Aristida sp., Schizachyrium sanguineum e Loudetiopsis chrysothrix (arbustos, subarbustos e ervas).

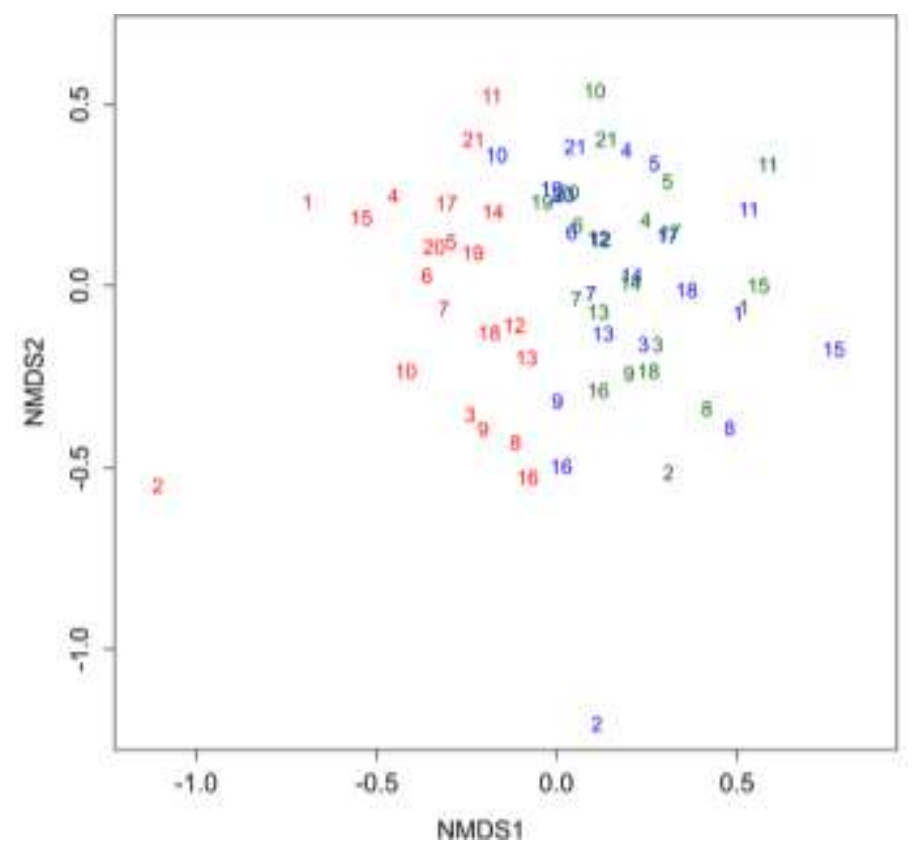

Figura 6. Ordenação escalonamento multidimensional não métrico (NMDS) mostrando o efeito do tempo na composição da comunidade baseado na composição e abundância de espécies (índice de similaridade de Bray-Curtis; stress 0.2419). Números representam parcelas, vermelho $=8$ meses, azul $=14$ meses, verde $=27$ meses. Tratamento baixa densidade: 1, 2, 3, 4, 5, 6, 7; média: 8, 9, 10, 11, 12, 13, 14; alta: 15, 16, 17, 18, 19, 20, 21. 


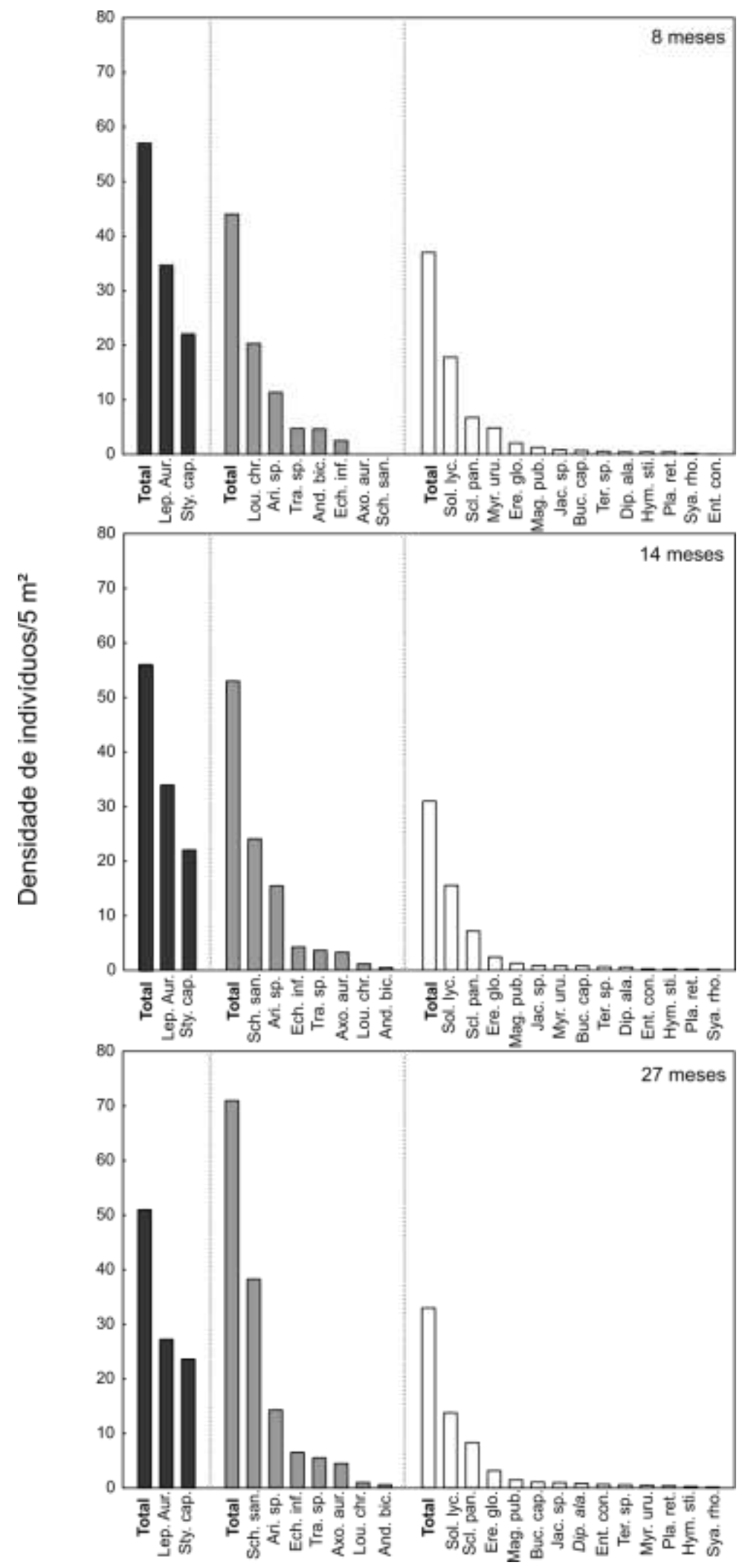

Figura 7. Densidade de indivíduos por espécie em $5 \mathrm{~m}^{2}$, aos 8,14 e 27 meses após a semeadura, nas classes arbustivas, herbáceas e arbóreas. Barras pretas representam espécies arbustivas, barras cinza representam espécies herbáceas e barras brancas espécies arbóreas (para abreviação das espécies, ver Tabela 1). 
2. Experimento Dinâmica de comunidades com diferentes composições iniciais

Parcelas com cobertura total inicial $\left(\mathrm{t}_{0}\right)$ abaixo de 150 toques apresentaram uma maior alteração da comunidade ao longo do tempo, independente se eram dominadas por nativas ou exóticas (Figura 8). Parcelas com mais de 150 toques na cobertura total inicial variaram menos, indicando que em parcelas com mais de 150 toques há redução do espaço disponível para o crescimento das plantas, limitando o aumento da cobertura ao longo do tempo (Figura 8). Em 64\% das parcelas houve aumento na cobertura relativa de espécies exóticas, enquanto 34\% apresentaram aumento na cobertura relativa de espécies nativas. A maioria das parcelas (73\%) que apresentou inicialmente mais que $70 \%$ de nativas permaneceu nessa faixa, e a maioria das parcelas $(82 \%)$ que apresentou mais que $70 \%$ de cobertura por espécies exóticas, também permaneceu nessa faixa. 


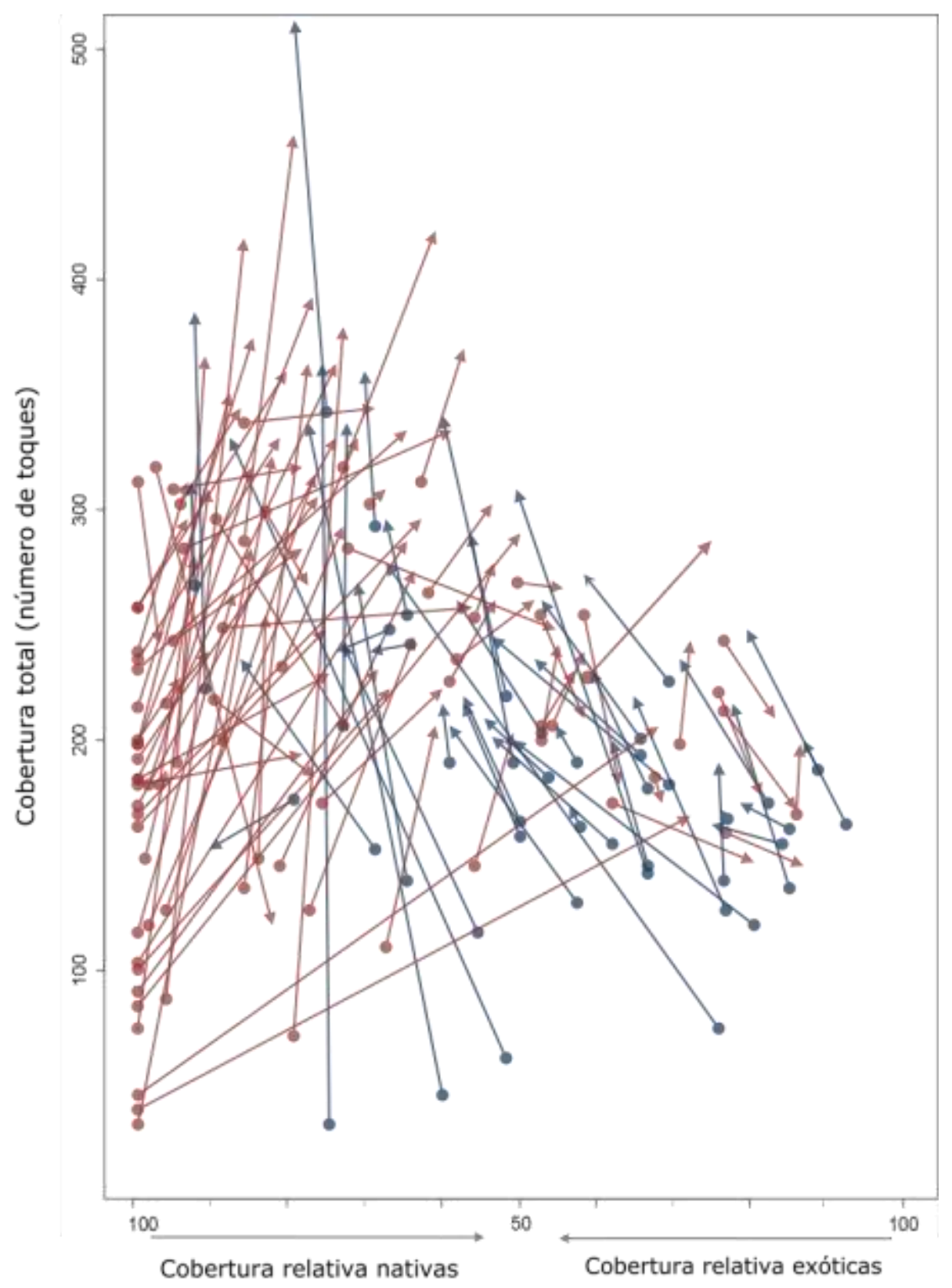

Figura 8. Cobertura relativa (\%) de espécies nativas/exóticas, por parcela de $1 \mathrm{~m}^{2}$. Cobertura total (considerada como número total de toques). Círculos representam valores no tempo inicial (2015) e setas representam valores das parcelas no tempo final (2016). Linhas vermelhas indicam direção de redução de espécies nativas com o tempo, consequência do aumento de exóticas, e linhas azuis indicam aumento de espécies nativas e redução conjunta de exóticas. 
A regressão logística foi a que apresentou melhor ajuste para os dados, tanto para espécies nativas $(\mathrm{r}=0,78)$, quanto para exóticas $(\mathrm{r}=0,79)$. Assim, onde havia pouca cobertura relativa, tanto de exóticas quanto de nativas, houve aumento da cobertura relativa ao longo do tempo, e o efeito de prioridade não foi verificado (Figura 9).

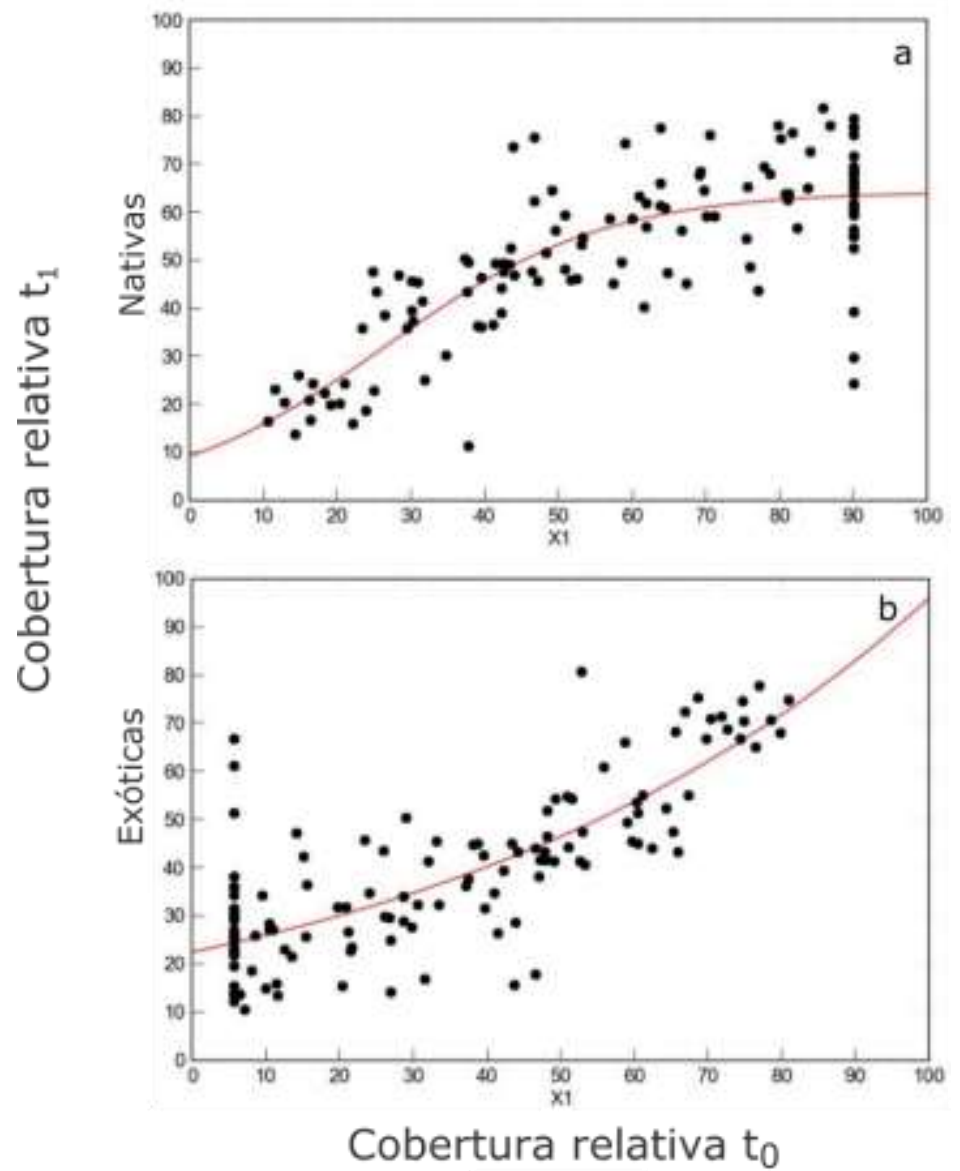

Figura 9. Regressão logística entre a. cobertura relativa de espécies nativas no tempo inicial e final e b. cobertura relativa de espécies nativas no tempo inicial e final.

De forma geral, houve alteração na comunidade de um ano para outro. Parcelas com mais de 388 toques, definido pela mediana, foram consideradas com alta cobertura e biomassa, e parcelas com menos de 388 toques, com baixa cobertura e biomassa. Houve correlação negativa entre o eixo 1 e 2 da NMDS no tempo inicial com o delta da parcela no eixo $1\left(t_{0}-t_{1}\right)$, para as parcelas com baixa biomassa (menos que 388 toques) $(\mathrm{r}=-0,67, \mathrm{p}<0,001 ; \mathrm{r}=-0,53, \mathrm{p}<0,001)$ e também houve forte correlação negativa para as 
parcelas com alta densidade de biomassa nos eixos 1 e 2 (mais que 388 toques) ( $r=-0,5$, $\mathrm{p}<0,001 ; \mathrm{r}=-0,54, \mathrm{p}<0,001)$, indicando que as parcelas com posição negativa nos eixos 1 e 2, se tornaram positivas e vice-versa (Figuras 10 e 11). A maioria das espécies exóticas está positivamente correlacionada ao eixo 2 , e a maioria das nativas está correlacionada negativamente aos eixos 1 e 2 , indicando distanciamento entre elas.

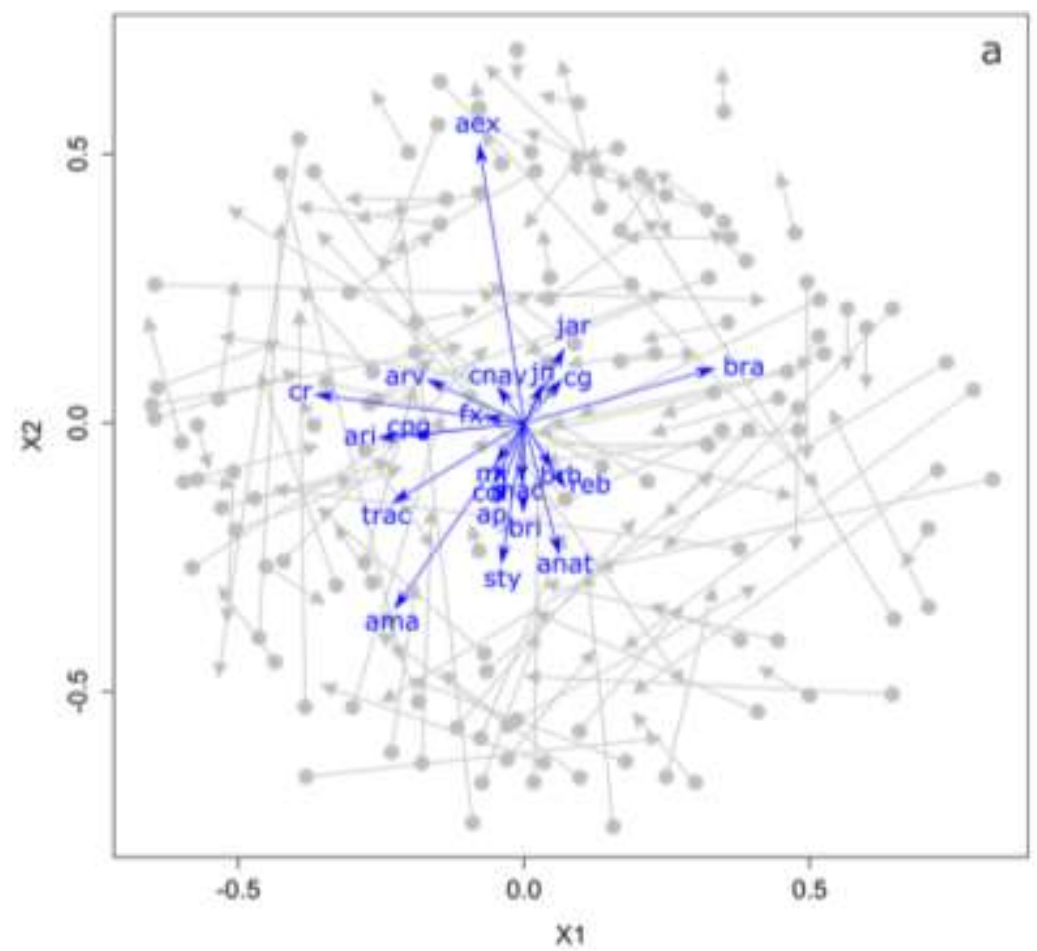

Figura 10. Escalonamento multidimensional não-métrico (NMDS) ordenando as parcelas com base na composição e abundância das espécies nativas e exóticas no tempo inicial (2015) e final (2016) (índice de similaridade de Bray-Curtis; stress 0.313); 

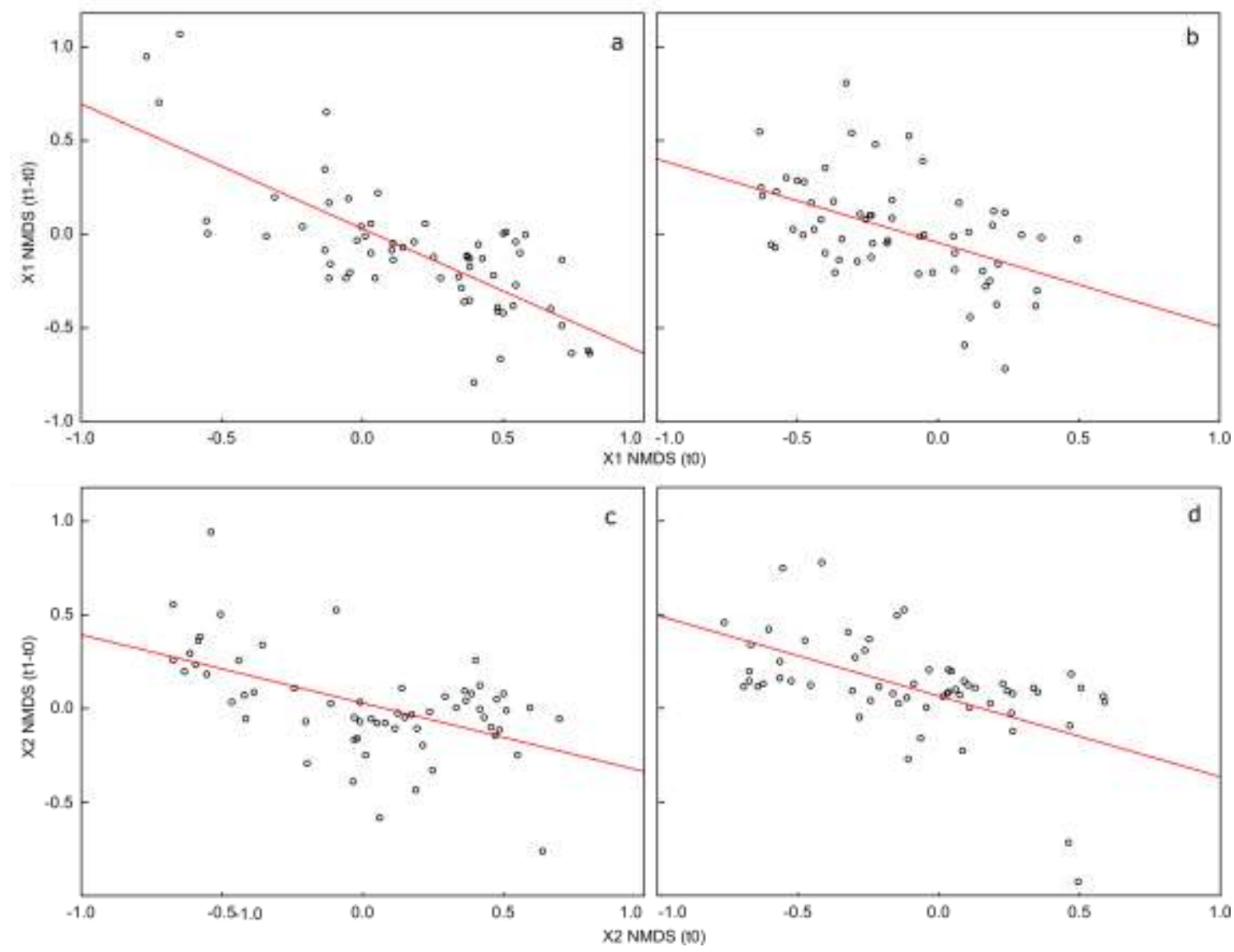

Figura 11. a. regressão entre eixo 1 da NMDS no tempo inicial, e delta da parcela no eixo 1, para parcelas com baixa densidade (menos que 388 toques); b. regressão entre eixo 1 da NMDS no tempo inicial, e delta da parcela no eixo 1, para parcelas com alta densidade (mais que 388 toques); c. regressão entre eixo 2 da NMDS no tempo inicial, e delta da parcela no eixo 2, para parcelas com baixa densidade (menos que 388 toques); d. regressão entre eixo 2 da NMDS no tempo inicial, e delta da parcela no eixo 2, para parcelas com alta densidade (mais que 388 toques).

\section{Discussão}

\section{As espécies de cerrado foram estabelecidas com sucesso}

Este estudo é um dos primeiros a demonstrar que é possível estabelecer espécies de gramíneas e arbustos, além de árvores nativas, em fitofisionomias abertas de Cerrado, pelo método de semeadura direta (veja também Pellizzaro et al., submetido). Após a semeadura direta de 23 espécies, 20 foram amostradas aos 8 meses e 22 aos 14 e 27 meses. Ao longo do tempo a cobertura e a densidade de espécies nativas plantadas aumentaram, sendo observada a reprodução de indivíduos semeados, germinação dessas 
sementes e estabelecimento de novos indivíduos para seis espécies. As espécies subarbustivas (Lepdaploa aurea e Stylosanthes capitata e Stylosanthes macrocephala) iniciaram com alta densidade e diminuíram aos 27 meses, provavelmente porque estão completando seu ciclo de vida e morrendo. Entretanto, L. aurea e Stylosanthes capitata e Stylosanthes macrocephala se reproduziram e novos indivíduos estão se estabelecendo nas áreas plantadas. As gramíneas nativas Schizachyrium sanguineum, Aristida sp., Echinolaena. inflexa, Axonopus aureus e Trachypogon sp. tiveram alta densidade de indivíduos e Schizachyrium sanguineum, especificamente, produziu alta densidade de novos indivíduos pela produção e germinação de sementes, possibilitando a manutenção da comunidade a longo prazo. Estes arbustos e gramíneas que germinam bem quando semeados, cobrem o solo e se reproduzem rapidamente são importantes componentes em projetos de restauração de fisionomias campestres e savânicas no Cerrado. Além disso, sua reprodução rápida tem potencial de colonizar mais manchas de solo exposto. Ervas crescem rapidamente, melhoram as características químicas, físicas e biológicas do solo e ajudam no controle da erosão (Silva e Corrêa, 2010). As árvores ocorrerem em uma densidade de 32 indivíduos $/ 5 \mathrm{~m}^{2}$ na área, tiveram um desenvolvimento lento e não cobriram o solo nos primeiros anos do plantio. É possível que nos próximos anos as árvores ocupem grande parte do estrato emergente da comunidade (Hill e Hanan, 2010) e tenham funções de buscar água em profundidade (Oliveira et al., 2005), gerando complexidade estrutural por servirem de refúgio, poleiro e fornecerem alimento para a fauna, atraindo dispersores e estimulando a sucessão (Ruiz-Jaen e Aide, 2005; Toh et al., 1999; West et al., 1981). Entretanto, a restauração de áreas nativas em que houve o estabelecimento de pastagem por longo período, apresenta cobertura de espécies nativas maior do que áreas de pastagem onde a 
gramínea exótica dominava, em que nenhuma atividade de restauração foi realizada (Pellizzaro, 2016).

\section{Mas estamos longe das áreas maduras}

É evidente que as espécies estudadas aqui são uma amostra mínima da riqueza florística do Cerrado. Trabalhos realizados na região do Distrito Federal e da Chapada dos Veadeiros registraram riqueza entre 55 e 97 espécies arbustivas e arbóreas, em áreas amostradas entre 1 e 15 ha (Almeida et al., 2014; Aquino et al., 2014; Felfili e Silva Junior, 2005; Felfili et al., 2003, 2001; Libano e Felfili, 2006), 92 e 163 para o estrato herbáceo-subarbustivo, em 80 m lineares (Munhoz e Felfili, 2006), e 557 para a flora vascular total, em 65 ha amostrados (Amaral et al., 2013). A introdução de novas espécies deve ser considerada, mas os fatores como dormência e sazonalidade de produção dificultam o uso de algumas espécies, e trabalhos que visem à obtenção de maiores informações sobre isso se tornam necessários. Além disso, a aquisição de sementes também pode representar um entrave, pois pouco se conhece sobre a prática da coleta de sementes de espécies herbáceas e arbustivas, que ainda é pouco difundida. $\mathrm{Na}$ Chapada dos Veadeiros, o programa de restauração usando o método da semeadura direta está crescendo. De acordo com o coletor Claudomiro de Almeida Cortes, que trabalha no projeto desde o início, no ano de 2015, 29 coletores trabalharam para coletar 6 toneladas de sementes de diversas espécies, semeadas em 33 ha, e em 2016, a previsão de coleta é de 15 toneladas, a serem semeadas em 60 ha. O número de indivíduos encontrados para as três formas de crescimento foi alto, comparado a estudos realizados em áreas de cerrado sentido restrito, que descrevem valores médios de 658 indivíduos/ha para arbustos, 1.482 indivíduos/ha para árvores, (Oliveira e Marquis, 2002), 1.148 indivíduos/ha para lenhosas (Almeida et al., 2014), 960 indivíduos/ha para 
o estrato arbustivo arbóreo (Aquino et al., 2014), 7.608 indivíduos/ha para herbáceas (Pivello et al., 1999), e 1.085 indivíduos/ha para monocotiledôneas em geral (Lenza et al., 2011). Entretanto, a comparação direta do número de indivíduos encontrados neste estudo com áreas mais conservadas de Cerrado deve ser cautelosa, pois há grande variação na composição e densidade de indivíduos entre as diferentes fitofisionomias abertas do bioma e a maioria dos estudos considera apenas espécies arbóreas, a partir de uma classe de tamanho mínima. Além disso, as áreas estudadas estão em estágio avançado de maturação, resultante de processos longos de interação entre espécies.

\section{Para melhorar o estabelecimento de nativas}

Não foram observadas novas espécies colonizando a área, além das plantadas, apesar de haverem áreas conservadas a cerca de 500 metros. O Cerrado é caracterizado pela limitação de sementes (Salazar et al., 2012), causada pela baixa densidade e baixa produção de sementes de árvores (Salazar et al., 2012) e por um estrato herbáceo graminoso predominantemente autocórico e anemocórico (Loiola et al., 2010) com pendões baixos que dificultam sua dispersão a longas distâncias. Apesar do número de indivíduos germinados e estabelecidos ter sido alto, as espécies nativas cobriram apenas $28 \%$ do solo aos 27 meses, o que permitiu $28 \%$ de solo exposto e $39 \%$ de exóticas. As árvores têm uma função importante na estrutura e composição do Cerrado, mas têm crescimento lento (Silva et al. 2015), atingindo uma média de $24 \mathrm{~cm}$ aos 36 meses na mesma área de estudo (Pellizaro et al. submetido), e terão maior influência na estrutura da comunidade a longo prazo. Ervas e arbustos semeadas em alta densidade ocuparam mais rapidamente a área, tendo maior potencial de prevenir a reinfestação de exóticas a curto prazo. Para isso, a densidade de sementes, principalmente de ervas e arbustos, pode ser maior do que a utilizada neste estudo. Sugerimos estudos direcionados à 
propagação em campo de espécies de ervas e arbustos, a fim de prospectar espécies, e aperfeiçoar técnicas de coleta, beneficiamento e semeadura de sementes que germinem e cubram o solo rapidamente, produzam sementes férteis para uma ocupação imediata do espaço, que poderia impedir a colonização de capins africanos. Além disso, muitas gramíneas nativas são classificadas como altamente tolerantes ao estresse, pois solos extremamente inférteis e improdutivos podem atuar como filtros ambientais, favorecendo espécies com atributos que conferem resistência ao estresse, o que pode garantir o estabelecimento delas no local (Aerts e Chapin, 2000; Grime et al., 1997; Negreiros e Le, 2014). A complementariedade de espécies vegetais pode ser vantajosa, com relação à estrutura da cobertura, fenologia e dinâmica no tempo e espaço, e por isso é indicado o uso de diversas espécies de cobertura em conjunto (Balandier et al., 2009).

\section{A disputa entre exóticas e nativas ainda está acontecendo}

Apesar de resultados concretos sobre o estabelecimento de espécies e de uma comunidade formada pela semeadura direta, ainda são necessários estudos mais longos para permitir uma melhor avaliação sobre os resultados da restauração. Enquanto houve aumento gradual na cobertura dessas espécies plantadas ao longo do tempo, a proporção de gramíneas exóticas também aumentou gradativamente e aos 27 meses teve cobertura similar às nativas. Além disso, a proporção de solo exposto ainda foi alta (29\%), deixando espaço tanto para espécies nativas quanto para exóticas se desenvolverem e colonizarem, considerando que o período amostrado foi curto.

Espécies exóticas podem ter estratégias que conferem vantagem na absorção de recursos (Schwinning e Weiner, 1998), garantindo seu sucesso de estabelecimento. Além disso, em campos nativos, a reduzida produção de biomassa mantém a disponibilidade de luz e solo para a ocupação, influenciando também o sucesso de 
estabelecimento de espécies exóticas (Manea et al., 2016). A sobrevivência de espécies nativas em área dominada pela gramínea exótica Mellinis minutiflora foi menor que $50 \%$ da sobrevivência em área dominada por espécies de gramíneas nativas, resultando em 60\% a menos de plântulas, ao final da terceira estação de crescimento (Hoffmann e Haridasan, 2008).

A germinação precoce confere vantagens no crescimento das gramíneas exóticas (Grman e Suding, 2010; Wainwright e Cleland, 2013). Por isso, reduzir o banco de sementes e as rebrotas de gramíneas exóticas, o máximo possível, conferiria a vantagem do estabelecimento antecipado de uma comunidade de espécies nativas, tornando-a mais resistente à invasão posterior das espécies exóticas. O estabelecimento de cobertura de gramíneas nativas, junto com o controle pré-semeadura resultaria em uma forte correlação negativa entre gramíneas exóticas e nativas (Young et al., 2015). Uma vez estabelecidas, as espécies que emergem primeiro podem manter o domínio, mesmo que nas próximas fases de vida sejam competidoras relativamente fracas (Abraham et al., 2009). Pastagens dominadas por gramíneas exóticas perenes foram reconvertidas em campos com maior cobertura de gramíneas nativas, suprimindo as exóticas por meio da roçada, em Oregon-EUA (Wilson e Clark, 2001). Técnicas que aumentam o estabelecimento inicial de densidade de gramíneas nativas perenes, mesmo com baixa cobertura, podem multiplicar essa cobertura ao longo do tempo, considerando a maturidade e reprodução desses indivíduos (Vaughn e Young, 2015).

\section{Controle de exóticas invasoras}

Neste estudo, o preparo do solo não eliminou o banco de sementes destas gramíneas, que germinaram simultaneamente às espécies nativas semeadas. Para evitar o restabelecimento rápido e abundante das gramíneas exóticas seria necessário um 
manejo prévio mais intenso, com mais intervenções de preparo de solo, para a remoção de propágulos. Alguns métodos são mais eficientes para isso. O uso de herbicidas específicos pode reduzir a parte aérea, controlar a germinação e impedir a rebrota futura de diversas plantas competidoras, principalmente se aplicado na fase inicial de desenvolvimento das exóticas. Além disso, o baixo custo permite a aplicação em projetos de larga escala (Ansley e Castellano, 2006; Bakker et al., 2003; Durigan et al., 1999; Nyamai et al., 2011; Toledo et al., 2003). Entretanto, para o uso de herbicidas na restauração de áreas ripárias, deve-se implementar faixas de vegetação para proteção, evitando que resíduos tóxicos presentes nos sedimentos sejam carreados até os corpos hídricos (Flórido, 2015). Outra limitação é que uso de herbicidas não é permitido em unidades de conservação no Brasil. A roçada das gramíneas exóticas, quando não estiverem produzindo sementes, e posterior cobertura do solo com esta a palhada elimina a parte aérea e limita a entrada de luz, reduzindo a germinação de sementes de espécies de gramíneas exóticas presentes no banco, além de reduzir a erosão, aumentar a umidade do solo e reduzir temperaturas extremas (Cox e Allen, 2008; Dostálek et al., 2006; Griscom et al., 2009; MacDougall e Turkington, 2005). A solarização, através da cobertura do solo por plástico preto pode reduzir a perda de nutrientes e também aumentar a umidade do solo, sendo eficiente no controle de plantas daninhas também por reduzir a entrada de luz (Regev et al., 1983; Ricotta e Masiunas, 1991). Tanto a cobertura com palhada quanto a solarização podem fornecer locais seguros para a germinação e proteção de mudas contra a dessecação em solos nus, mas tanto na cobertura com palhada quanto na solarização, mas a germinação e o estabelecimento de plântulas nativas de espécies exigentes em luz podem ser prejudicadas (Donath et al., 2006; Eckstein and Donath, 2005). A remoção da camada superficial do solo, com escavadeira a uma profundidade aproximada de $30 \mathrm{~cm}$, suprime a vegetação e remove o 
banco de sementes de espécies exóticas usadas para pastagem, mas pode também eliminar o banco de sementes de nativas e diminuir a fertilidade do solo (Buisson et al., 2006; Grman e Suding, 2010; Rasran et al., 2007). O fogo também pode ser uma boa forma de controle de espécies exóticas invasoras. Em áreas abertas de Cerrado, são indicadas queimadas controladas no começo do inverno (início da estação seca) (Pivello and Norton, 1996). Se as gramíneas exóticas invasoras estiverem presentes em alta densidade, pode ser necessário mais de uma queimada, dependendo da eficiência das queimadas. Porém, este método pode aumentar a susceptibilidade a erosão e a exposição a altas temperaturas pode aumentar a mortalidade de sementes e brotos após terem sido expostos a altas temperaturas (Gorgone-Barbosa et al., 2015). O preparo do solo também é de grande importância no controle das gramíneas exóticas, pois tritura e elimina parte delas (Donath et al., 2007; Durigan et al., 2013, 1998; Grygiel et al., 2009; Kiehl et al., 2010), com o uso de implementos que danifiquem a parte aérea e as raízes, e exponham as sementes das exóticas ao sol. Neste experimento, o preparo do solo foi feito através de grade aradora apenas, que pode não ter sido suficiente na eliminação do banco de sementes e rebrota de gramíneas exóticas. Muitas vezes, é necessária a combinação de técnicas para o controle ser eficiente, e o manejo dessas áreas pode requerer esforços repetidos de controle, eliminando as plantas que emergirem (Carmona, 1992; Cox e Allen, 2008). A roçagem (no caso da gramínea apresentar alta biomassa aérea), seguida de preparo do solo com subsolador e grade, e posterior aplicação de herbicida, pode ser uma combinação eficiente. 


\section{O papel do Stylosanthes}

Neste estudo, a hipótese de que um gênero de arbusto comercial plantado em alta densidade poderia prevenir a emergência de espécies exóticas não se confirmou, a densidade de Stylosanthes capitata e Stylosanthes macrocephala foi insuficiente para cobrir o solo, mesmo na densidade mais alta aplicada. A grande variação de Stylosanthes capitata e Stylosanthes macrocephala nas parcelas pode ter ocorrido por diferenças na semeadura. Enquanto sua cobertura maciça poderia impedir a ocupação pelas gramíneas exóticas, sua presença moderada poderia favorecer o desenvolvimento das espécies exóticas, pois trata-se de uma leguminosa que possui associação com bactérias fixadoras de nitrogênio (Vitor et al., 2008). A semeadura em quantidade maior do que a que ocorre naturalmente em vegetação nativa de Cerrado pode ter promovido um aumento na disponibilidade de Nitrogênio, favorecendo as espécies exóticas (Daehler, 2003). Estudos utilizando o Stylosanthes em consórcio com espécies de Brachiaria, Andropogon e Panicum constataram que o Nitrogênio fixado promoveu um aumento de até 50\% na biomassa da pastagem (Campos Paciullo et al., 2003; Macedo et al., 2014; Soares De Andrade et al., 2003). Entretanto, Silva e Corrêa (2008) observaram um maior crescimento de espécies arbóreas quando plantadas em consórcio com Stylosanthes capitata e Stylosanthes macrocephala.

Stylosanthes é um gênero da família Fabaceae, que pode suprimir plantas invasoras (Phengsavanh e Ledin, 2003). Plantas desse gênero são adaptadas a uma ampla variedade de condições ambientais, e incluem diversas espécies nativas do Cerrado (Karia et al., 2002). São espécies que se desenvolvem bem em solos pobres, em uma ampla faixa de $\mathrm{pH}$, são tolerantes à seca e associadas à bactérias fixadoras de nitrogênio, e tais características beneficiam a reabilitação do solo (Phengsavanh e 
Ledin, 2003). A semeadura de Stylosanthes capitata e Stylosanthes macrocephala, para avaliar sua influência na reabilitação de uma mina de cascalho em região de Cerrado, promoveu aumento de mais de 50\% de indivíduos e 30\% mais espécies, apresentando maior diversidade quando comparada à área controle, sem semeadura. Além disso, Stylosanthes capitata e Stylosanthes macrocephala aumentaram também a fertilidade do solo exposto, demonstrando que o uso dessas espécies perenes como cobertura vegetal permite o estabelecimento de uma comunidade de plantas com uma melhor qualidade ecológica (Starr et al., 2013).

\section{Implicações para a prática}

A semeadura direta é uma boa técnica para introdução de espécies de todos os estratos de formações de Cerrado. O estudo e a inclusão de novas espécies é importante para aumentar as funções e a estrutura do sistema, e criar uma comunidade biodiversa que se perpetue. O controle inicial adequado das gramíneas exóticas é necessário para reduzir seu desempenho e densidade, possibilitando o desenvolvimento da comunidade nativa. A coleta de sementes pode ser uma limitação, entretanto, a restauração pelo método de semeadura constitui um estímulo à criação local desse mercado de sementes e esta técnica apresenta, de forma geral, custos muito reduzidos em relação a outros métodos de plantio. A partir dos resultados deste estudo, é possível dizer que apesar da presença de gramíneas exóticas, as espécies nativas semeadas estão se reproduzindo, gerando novos indivíduos e estabelecendo uma comunidade, que ao longo do tempo irá se perpetuar e se desenvolver em conjunto com tais espécies exóticas.

\section{Referências bibliográficas}

Abraham, J.K., Corbin, J.D., D'Antonio, C.M., 2009. California native and exotic perennial grasses differ in their response to soil nitrogen, exotic annual grass density, 
and order of emergence. Plant Ecology 201.2: 445-456.

Aerts, R., Chapin, F.S., 1999. The Mineral Nutrition of Wild Plants Revisited: A Reevaluation of Processes and Patterns. Advances in ecological research 30:1-67.

Aide, T.M., 2000. Clues for Tropical Forest Restoration. Restoration Ecology 8.4: 327.

Almeida, R.F., Fagg, C.W., Oliveira, M.C. De, Munhoz, C.B.R., Lima, A.S. De, Oliveira, L.S.B. de, 2014. Mudanças florísticas e estruturais no cerrado sensu stricto ao longo de 27 anos (1985-2012) na Fazenda Água Limpa, Brasília, DF RodriguésiaInstituto de Pesquisas Jardim Botânico do Rio de Janeiro 65.1: 001-019.

Amaral, A.G., Munhoz, C.B.R., Ulysses Orlando Eugênio, C., Felfili, J.M., 2013. Vascular flora in dry-shrub and wet grassland Cerrado seven years after a fire, Federal District, Brasil.

Andrade, B.O., Koch, C., Boldrini, I.I., Vélez-Martin, E., Hasenack, H., Hermann, J.M., Kollmann, J., Pillar, V.D., Overbeck, G.E., 2015. Grassland degradation and restoration: a conceptual framework of stages and thresholds illustrated by southern Brazilian grasslands. Natureza \& Conservação 13.2: 95-104.

Ansley, R.J., Castellano, M.J., 2006. Strategies for savanna restoration in the southern Great Plains: Effects of fire and herbicides. Restoration Ecology 14.3: 420-428.

Aquino, F.D.G., Pereira, C.S., Passos, F.B., de Oliveira, M.C., 2014. Composição florística e estrutural de um Cerrado sentido restrito na área de proteção de manancial Mestre D’Armas, Distrito Federal. Bioscience Journal 30.2.

Raven, Peter H. Restoring natural capital: science, business, and practice, 2012. Eds. James Aronson, Suzanne J. Milton, and James N. Blignaut. Island press.

Bakker, J.D., Wilson, S.D., Christian, J.M., Li, X., Ambrose, L.G., Waddington, J., 2003. Contingency of grassland restoration on year, site, and competition from introduced grasses. Ecological applications 13.1: 137-153.

Bakker, J.P., Berendse, F., 1999. Constraints in the restoration of ecological diversity in grassland and heathland communities. Trends in ecology \& evolution 14.2: 63-68.

Balandier, P., Frochot, H., Sourisseau, A., 2009. Improvement of direct tree seeding with cover crops in afforestation: Microclimate and resource availability induced by vegetation composition. Forest ecology and management 257.8: 1716-1724.

Brandt, A.J., Seabloom, E.W., 2012. Seed and establishment limitation contribute to long- term native forb declines in California grasslands. Ecology 93.6: 1451-1462.

Buisson, E., Holl, K.D., Anderson, S., Corcket, E., Hayes, G.F., Torre, F., Peteers, A., Dutoit, T., 2006. Effect of seed source, topsoil removal, and plant neighbor removal on restoring California coastal prairies. Restoration Ecology 14.4: 569-577.

Calviño-Cancela, M., 2007. Seed and microsite limitations of recruitment and the impacts of post-dispersal seed predation at the within population level. Plant Ecology 192.1: 35-44.

Campos Paciullo, D.S., Magalhães Aroeira, L.J., Alvim, M.J., Mesquita Carvalho, M., 2003. Características produtivas e qualitativas de pastagem de braquiária em monocultivo e consorciada com estilosantes. Pesquisa Agropecuária Brasileira 
38.3: $421-426$.

Campos-Filho, E.M., Da Costa, J.N.M.N., De Sousa, O.L., Junqueira, R.G.P., 2013. Mechanized Direct-Seeding of Native Forests in Xingu, Central Brazil. Journal of sustainable forestry 32.7: 702-727.

Carbone, M., Siqueira, J., F, D.S., 2001. Establishment of herbaceous plants in heavy metal contaminated soils inoculated with arbuscular mycorrhizal fungi. Pesquisa Agropecuária Brasileira 36.12: 1443-1452.

Carmona, R., 1992. Problemática e manejo de bancos de sementes. Planta daninha 10.1/2: 5-16.

Celis, G., Jose, S., 2011. Restoring abandoned pasture land with native tree species in Costa Rica: Effects of exotic grass competition and light. Forest Ecology and Management 261.10: 1598-1604.

Chazdon, R.L., 2008. Beyond deforestation: restoring forests and ecosystem services on degraded lands. Science 320.5882: 1458-1460.

Clark, J.S., Macklin, E., Wood, L., 1998. Stages and spatial scales of recruitment limitation in southern Apalachian forests. Ecological Monographs 68.2: 213-235

Coleman, H.M., Levine, J.M., 2007. Mechanisms underlying the impacts of exotic annual grasses in a coastal California meadow. Biological Invasions 9.1: 65-71.

Corbin, J.D., D'Antonio, C.M., 2004. Competition between native perennial and exotic annual grasses: Implications for an historical invasion. Ecology 85.5: 1273-1283.

Corr, K., 2003. Revegetation Techniques. A guide for establishing native vegetation in Victoria. Greening Australia.

Cox, R.D., Allen, E.B., 2008. Stability of exotic annual grasses following restoration efforts in southern California coastal sage scrub. Journal of Applied Ecology 45.2: 495-504.

D'Antonio, C.M., Vitousek, P.M., 1992. Biological invasions by exotic grasses, the grass/fire cycle, and global change. Annual review of ecology and systematics 23: 63-87.

Daehler, C.C., 2003. Performance comparisons of co-occurring native and alien invasive plants: Implications for conservation and restoration. Annual Review of Ecology, Evolution, and Systematics 183-211.

Dickson, T.L., Hopwood, J.L., Wilsey, B.J., 2012. Do priority effects benefit invasive plants more than native plants? An experiment with six grassland species. Biological Invasions 14.12: 2617-2624.

Diniz-filho, J.A.F., Oliveira, G. De, Lobo, F., Guimarães, L., 2009. Agriculture, habitat loss and spatial patterns of human occupation in a biodiversity hotspot. Scientia Agricola 66.6: 764-771.

Donath, T.W., Bissels, S., Ho, N., Otte, A., 2007. Large scale application of diaspore transfer with plant material in restoration practice - Impact of seed and microsite limitation. Biological Conservation 138.1: 224-234. 
Donath, T.W., Ho, N., Otte, A., 2006. Influence of competition by sown grass, disturbance and litter on recruitment of rare flood-meadow species. Biological conservation 130.3: 315-323

Dostálek, J., Weber, M., Matula, S., Frantík, T., 2007. Forest stand restoration in the agricultural landscape: The effect of different methods of planting establishment. Ecological Engineering 29.1: 77-86.

Durigan, G., Contieri, W.A., Franco, G.A.D.C., Garrido, M.A.O., 1998. Indução do processo de regeneração da vegetação de Cerrado em área de pastagem, Assis, SP. Acta Botanica Brasilica 12.3: 421-429.

Durigan, G., Guerin, N., da Costa, J.N.M.N., 2013. Ecological restoration of Xingu Basin headwaters: motivations, engagement, challenges and perspectives. Philosophical Transactions of the Royal Society of London B: Biological Sciences 368.1619: 20120165.

Dyer, A.R., Rice, K.J., 1999. Effects of competition on resource availability and growth of a Californian bunchgrass. Ecology 80.8: 2697-2710.

Eckstein, R.L., Donath, T.W., 2005. Interactions between litter and water availability affect seedling emergence in four familial pairs of floodplain species. Journal of Ecology 93.4: 807-816.

Eiten, G., 1972. The cerrado vegetation of Brazil. The Botanical Review 38.2: 201-341.

EMBRAPA, 1993. Recomendações para estabelecimento e utilização do Stylosanthes guianensis cv. Mineirão. Campo Grande: EMBRAPA-CNPGC (Comunicado Técnico, 49) 6 .

Emery, S.M., 2007. Limiting similarity between invaders and dominant species in herbaceous plant communities? Journal of Ecology 95.5: 1027-1035.

Engel, V.L., Parrotta, J. a, 2001. An evaluation of direct seeding for reforestation of degraded lands in central São Paulo state, Brazil. Forest Ecology and Management 152.1: 169-181.

Eriksson, O., Erlhén, J., 1992. Seed and microsite limiation of recruitment in plant populations. Oecologia 91.3: 360-364.

Falk, D.A., Palmer, M.A., Zedler, J.B., 2006. Foundations of Restoration Ecology. Washington, DC: Island Press.

Fargione, J., Brown, C.S., Tilman, D., 2003. Community assembly and invasion: An experimental test of neutral versus niche processes. Proceedings of the National Academy of Sciences 100.15: 8916-8920.

Favreto, R., Medeiros, R.B. De, Levien, R., 2005. Vegetação espontânea em lavoura sob diferentes manejos estabelecida sobre campo natural. Iheringia-Série Botânica, Porto Alegre.

Felfili, J. M., 2007. A chapada dos veadeiros. Biogeografia do Bioma Cerrado: Vegetação e Solos da Chapada dos Veadeiros. Editora Universidade de Brasília, Brasilia.

Felfili, J.M., da Silva Júnior, M.C., Sevilha, A.C., Fagg, C.W., Walter, B.M.T., 
Nogueira, P.E. and Rezende, A.V., 2004. Diversity, floristic and structural patterns of cerrado vegetation in Central Brazil. Plant Ecology, 175.1: 37-46.

Felfili, J.M., Manoel Cláudio da Silva Junior, 2005. Diversidade alfa e beta no cerrado sensu strictu, Distrito Federal, Goiás, Minas Geria e Bahia. Cerrado: ecologia, biodiversidade e conservação. Brasília: Ministério do Meio Ambiente 141-154.

Felfili, J.M., Sevilha, A.C., Manoel Cláudio da Silva Junior, 2001. Comparação entre as unidades fisiográficas Chapada Pratinha, Veadeiros e Espigão Mestre do São Francisco. Biogeografia do bioma Cerrado: estudo fitofisionômico da Chapada do Espigão Mestre do São Francisco (JM Felfili \& MC Silva Júnior, orgs.). UnB, Brasília 80-152.

Fenner, M., 2000. Seeds: the ecology of regeneration in plant communities. Cabi.

Ferraz, I., Válio, M., Scarpa, F.M., 2001. Germination of seeds of tropical pioneer species under controlled and natural conditions. Brazilian Journal of Botany 24.1: 7984.

Flórido, F.G., 2015. Controle de plantas competidoras na restauração ecológica. Diss. Universidade de São Paulo.

Foster, B.L., Murphy, C. a., Keller, K.R., Aschenbach, T. a., Questad, E.J., Kindscher, K., 2007. Restoration of prairie community structure and ecosystem function in an abandoned hayfield: a sowing experiment. Restoration Ecology 15.4: 652-661.

Freitas, G. D., Pivello, V. R., PIVELLO, V., VARANDA, E, 2005. A ameaça das gramíneas exóticas à biodiversidade. O Cerrado Pé-de-Gigante (Parque Estadual de Vassununga, São Paulo). Ecologia e Conservação 283-296.

Fukami, T., 2015. Historical Contingency in Community Assembly: Integrating Niches, Species Pools, and Priority Effects. Annual Review of Ecology, Evolution, and Systematics 46.1: 1 .

Fukami, T., Bezemer, T.M., Mortimer, S.R., Van Der Putten, W.H., 2005. Species divergence and trait convergence in experimental plant community assembly. Ecology Letters 8.12: 1283-1290.

Funk, J.L., 2013. The physiology of invasive plants in low-resource environments. Conservation Physiology 1.1: $\cot 026$.

Funk, J.L., Cleland, E.E., Suding, K.N., Zavaleta, E.S., 2008. Restoration through reassembly: plant traits and invasion resistance. Trends in ecology \& evolution 23.12: 695-703.

Goiás, 2006. Secretaria de Indústria e Comércio. Superintendência de Geologia e Mineração. Caracterização Climática do Estado de Goiás. Por Silvando Carlos da Silva, Neiva Maria Pio de Santana, José Cardoso Pelegrini. Goiânia.

Gorgone-Barbosa, E., Pivello, V.R., Bautista, S., Zupo, T., Rissi, M.N., Fidelis, A., 2015. How can an invasive grass affect fire behavior in a tropical savanna? A community and individual plant level approach. Biological Invasions 17.1: 423-431.

Goudel, F., Maria, C., Coelho, M., Richard, P., Miller, M., 2013. Fruit biometry and seed germination of Syagrus romanzoffiana (Cham.) Glassm . Acta Botanica Brasilica 27.1: 147-154. 
Grime, J.P., Thompson, K., Hunt, R., Hodgson, J.G., Cornelissen, J.H.C., Rorison, I.H., Hendry, G.A.F., Ashenden, T.W., Askew, A.P., Band, S.R. and Booth, R.E., 1997. Integrated screening validates primary axes of specialisation in plants. Oikos 259-281.

Griscom, H.P., Griscom, B.W., Ashton, M.S., 2009. Forest regeneration from pasture in the dry tropics of panama: effects of cattle, exotic grass, and forested riparia. Restoration Ecology 17.1: 117-126.

Grman, E., Suding, K.N., 2010. Within-year soil legacies contribute to strong priority effects of exotics on native california grassland communities. Restoration Ecology 18.5: 664-670.

Grubb, B.Y.P.J., 1977. The maintenance of species-richness in plant communitites: the importance of the regeneration niche. Biological reviews 52.1: 107-145.

Grygiel, C.E., Norland, J.E., Biondini, M.E., 2009. Precision prairie reconstruction (PPR): a technique for increasing native forb species richness in an established grass matrix. Ecological Restoration 27.4: 458-466.

Haridasan, M., 2007. Solos, in: Felfili, J.M., Rezende, A.V., Júnior, M.C. da S. (Eds.), Biogeografia do Bioma Cerrado: vegetação e solos da Chapada dos Veadeiros. Universidade de Brasília, Brasília, 25-43.

Haridasan, M., 1982. Aluminium accumulation by some cerrado native species of central Brazil. Plant Soil 65: 265-273.

Hill, Michael J., and Niall P. Hanan, 2010. eds. Ecosystem function in savannas: Measurement and modeling at landscape to global scales. CRC Press.

Hobbes, R.J., Norton, D.A., 1996. Towards a conceptual framewor for restoration ecology. Restorations Ecology, 4: 93-110.

Hoffmann, W.A., Haridasan, M., 2008. The invasive grass , Melinis minutiflora, inhibits tree regeneration in a Neotropical savanna. Austral Ecology 33.1: 29-36.

Holl, K., Loik, M., Lin, E., Samuels, I., 2000. Tropical montane forest restoration in Costa Rica: overcoming barriers to dispersal and establishment. Restoration ecology 8.4: 339-349.

Holl, K.D., 1999. Factors limiting tropical rain forest regeneration in abandoned pasture : seed rain, seed germination, microclimate, and soil. Biotropica 31: 229-242.

Hyams, D.G., 2010. CurveExpert software.

ICMBio, 2009. Plano de Manejo do Parque Nacional Chapada dos Veadeiros.

Interagency Technical Team (ITT), 1996. Sampling vegetation attributes, interagency technical reference, Teaching.

Karia, C.T., Andrade, R.P., Charchar, M.J.A., Gomes, A.C., 2002. Caracterização morfológica de acessos do gênero Stylosanthes no banco ativo da EMBRAPA Cerrados - Coleção 1994/1995, Boletim de Pesquisa e Desenvolvimento.

Khan, M.L., 2013. Effects of seed weight and microsite characteristics on germination and seedling fitness in two species of Quercus in a subtropical wet hill forest. Oikos 289-296. 
Kiehl, K., Kirmer, A., Donath, T.W., Rasran, L., Hölzel, N., 2010. Species introduction in restoration projects - Evaluation of different techniques for the establishment of seminatural grasslands in Central and Northwestern Europe. Basic and Applied Ecology 11.4: 285-299.

Kimball, S., Lulow, M.E., Mooney, K.A., Sorenson, Q.M., 2014. Establishment and management of native functional groups in restoration. Restoration ecology 22.1: 81-88.

Kleunen, M. van, 2010. A meta-analysis of trait differences between invasive and noninvasive plant species. Ecology letters 13.2: 235-245.

Klink, C. a., Machado, R.B., 2005. Conservation of the Brazilian Cerrado. Conservation biology 19.3: 707-713.

Klink, C.A., 1996. Germination and seedling establishment of two native and one invading African grass species in the Brazilian cerrado. Journal of tropical Ecology 12.1: 139-147.

Klink, C.A., Moreira, A.G., 2002. Past and current human occupation, and land use. The cerrados of Brazil: ecology and natural history of a neotropical savanna 69-88.

Knight, a. J.P., Beale, P.E., Dalton, G.S., 1997. Direct seeding of native trees and shrubs in low rainfall areas and on non-wetting sands in South Australia. Agroforestry Systems 39.3: 225-239.

Lenza, E., Klink, C.A., 2006. Comportamento fenológico de espécies lenhosas em um cerrado sentido restrito de Brasília, DF. Revista Brasileira de Botânica 29.4: 627-638.

Lenza, E., Pinto, J.R.R., Pinto, A. de S., Maracahipes, L., Bruziguessi, E.P., 2011. Comparação da vegetação arbustivo-arbórea de uma área de cerrado rupestre na Chapada dos Veadeiros, Goiás, e áreas de cerrado sentido restrito do Bioma Cerrado. Revista Brasileira de Botânica 34.3: 247-259.

Liao, H., Luo, W., Peng, S., Callaway, R.M., 2015. Plant diversity, soil biota and resistance to exotic invasion. Diversity and Distributions 21.7: 826-835

Libano, A.M., Felfili, J.M., 2006. Mudanças temporais na composição florística e na diversidade de um cerrado sensu stricto do Brasil Central em um período de 18 anos (1985-2003). Acta Botanica Brasilica 20: 927-936.

Loiola, P.D.P., Cianciaruso, M.V., Silva, I.A., Batalha, M.A., 2010. Functional diversity of herbaceous species under different fire frequencies in Brazilian savannas. FloraMorphology, Distribution, Functional Ecology of Plants 205.10: 674-681

MacDougall, A.S., Turkington, R., 2005. Are invasive species the drivers or passengers of change in degraded ecosystems? Ecology 86.1: 42-55.

Macedo, M.C.M.., Zimmer, A.H.., Kichel, A.N.., Almeida, R.G.., Araujo, A.R., 2014. Degradação de pastagens, alternativas de recuperação e renovação, e formas de mitigação. Encontro adubaçao pastagens da Scot Consult. - Tec - Fértil. 158-181.

Manea, A., Sloane, D.R., Leishman, M.R., 2016. Reductions in native grass biomass associated with drought facilitates the invasion of an exotic grass into a model grassland system. Oecologia 181.1: 175-183.

Mangla, S., James, J.J., Radosevich, S.R., 2011. Intra and interspecific competition 
among invasive and native species during early stages of plant growth. Plant Ecology 212.4: 531-542.

Martins, S.V., 2015. Restauração ecológica de ecossistemas degradados, 2nd ed. Ed. UFV, Viçosa, MG.

Mason, T.J., French, K., 2008. Impacts of a woody invader vary in different vegetation communities. Diversity and Distributions 14.5: 829-838.

Matzek, V., 2012. Trait values, not trait plasticity, best explain invasive species' performance in a changing environment. PLoS One 7.10: e48821.

Miranda, H.S., Sato, M.N., Neto, W.N., Aires, F.S., 2009. Fires in the cerrado, the Brazilian savanna. Tropical Fire Ecology. Springer Berlin Heidelberg 427-450.

MMA, 2015. Mapeamento do Uso e Cobertura do Cerrado: Projeto TerraClass Cerrado.

Muller-Landau, H.C., Wright, S.J., Calderón, O., Hubbell, S.P., Foster, R.B., 2002. Assessing recruitment limitation: concepts, methods and case-studies from a tropical forest. Seed dispersal and frugivory: Ecology, evolution and conservation 35-53.

Munhoz, C.B.R., Felfili, J.M., 2006. Fitossociologia do estrato herbáceo-subarbustivo de uma área de campo sujo no Distrito Federal, Brasil. Acta Botanica Brasilica 20.3: 671-685.

Murphy, C.A., Foster, B.L., Ramspott, M.E., Kevin, P., 2004. Grassland management effects on soil bulk density.Transactions of the Kansas Academy of Science 107.1: 4554.

Negreiros, D., Le, S., 2014. CSR analysis of plant functional types in highly diverse tropical grasslands of harsh environments. Plant ecology 215.4: 379-388.

Nyamai, P. a., Prather, T.S., Wallace, J.M., 2011. Evaluating restoration methods across a range of plant communities dominated by invasive annual grasses to native perennial grasses. Invasive Plant Science and Management 4.3: 306-316.

Oliveira, Paulo S., and Robert J. Marquis. The cerrados of Brazil: ecology and natural history of a neotropical savanna. Columbia University Press.

Oliveira, R.S., Davidson, E.A., Klink, C.A., Moreira, A., 2005. Deep root function in soil water dynamics in cerrado savannas of central Brazil. Functional Ecology 19.4: 574-581.

Overbeck, G.E., Vélez- Martin, E., Scarano, F.R., Lewinsohn, T.M., Fonseca, C.R., Meyer, S.T., Müller, S.C., Ceotto, P., Dadalt, L., Durigan, G. and Ganade, G., 2015. Conservation in Brazil needs to include non- forest ecosystems. Diversity and Distributions, 21.12: 1455-1460

Parr, C.L., Lehmann, C.E.R., Bond, W.J., Hoffmann, W.A., Andersen, A.N., 2014. Tropical grassy biomes: misunderstood, neglected, and under threat. Trends in ecology \& evolution 29.4: 205-213.

Pellizzaro, Keiko Fueta, 2016. Restauração ecológica por meio de semeadura direta no Cerrado: avaliando espécies de diferentes formas de vida e densidades de plantio.

Pellizzaro, K.F., Cordeiro, A.O.O., Alves, M., Motta, C.P., Rezende, G.M., Silva, 
R.R.P., Sampaio, A.B., Vieira, D.L.M., Schmid, I.B., n.d. Can we restore Neotropical savannas through direct seeding? Filed establishment and initial growth of 75 trees, shrubs and grass species. In press.

Pérez-Harguindeguy, N., Díaz, S., Garnier, E., Lavorel, S., Poorter, H., Jaureguiberry, P., Bret-Harte, M.S., Cornwell, W.K., Craine, J.M., Gurvich, D.E. and Urcelay, C., 2013. New handbook for standardised measurement of plant functional traits worldwide. Australian Journal of botany 61.3:167-234.

Phengsavanh, P., Ledin, I., 2003. Effect of Stylo 184 (Stylosanthes guianensis CIAT 184) and Gamba grass (Andropogon gayanus cv. Kent) in diets for growing goats. Livestock Research for Rural Development 15.10.

Pivello, Vânia Regina, et al., 1999. Abundance and distribution of native and alien grasses in a "Cerrado"(Brazilian Savanna) biological reserve1. Biotropica 31.1: 71-82.

Pivello, V.R., Coutinho, L.M., 1996. A qualitative successional model to assist in the management of Brazilian cerrados. Forest Ecology and Management 87.1: 127-138.

Pivello, V.R., Norton, G.A., 1996. Firetool: an expert system for the use of prescribed fires in brazilian savannas. Journal of Applied Ecology 348-356.

Pivello, V.R., Shida, C.N., Meirelles, S.T., 1999. Alien grasses in Brazilian savannas: a threat to the biodiversity. Biodiversity \& Conservation 8.9: 1281-1294.

Prober, S.M., Thiele, K.R., Lunt, I.D., Koen, T.B., 2005. Restoring ecological function in temperate grassy woodlands: manipulating soil nutrients, exotic annuals and native perennial grasses through carbon supplements and spring burns. Journal of Applied Ecology 42.6: 1073-1085.

Rasran, L., Vogt, K., Jensen, K., 2007. Effects of topsoil removal, seed transfer with plant material and moderate grazing on restoration of riparian fen grasslands. Applied Vegetation Science 10.3: 451-460.

Ratter, J.A., Ribeiro, J.F. and Bridgewater, S., 1997. The Brazilian cerrado vegetation and threats to its biodiversity. Annals of botany, 80.3: 223-230.

Horowitz, M., Regev, Y. and Herzlinger, G., 1983. Solarization for weed control. Weed Science 170-179.

Ribeiro, J.F., Walter, B.M.T., 2008. As Principais Fitofisionomias do Bioma Cerrado, in: Sano, S.M., de Almeida, S.P., Ribeiro, J.F. (Eds.), Cerrado: Ecologia e Flora. Embrapa Informação Tecnológica, Brasília, DF 89-166.

Rice, K.J., Dyer, A.R., 2001. Seed aging, delayed germination and reduced competitive ability in Bromus tectorum. Plant Ecology 155.2: 237-243.

Ricotta, J.A., Masiunas, J.B., 1991. The effects of black plastic mulch and weed control strategies on herb yield HortScience 26.5: 539-541.

Roberts, R.E., Clark, D.L., Wilson, M. V, 2010. Traits, neighbors, and species performance in prairie restoration. Applied Vegetation Science 13.3: 270-279.

Ross, D. a., Harper, J.L., 1972. Occupation of biological space during seedling establishment. The Journal of Ecology 77-88 
Ruiz-Jaen, M.C., Aide, T.M., 2005. Restoration success: how is it being measured? Restoration ecology 13.3: 569-577.

Salazar, A., Goldstein, G., Franco, A.C., Miralles-Wilhelm, F., 2012. Seed limitation of woody plants in Neotropical savannas. Plant Ecology 213.2: 273-287.

Sampaio, A.B., Holl, K.D., Scariot, A., 2007. Does restoration enhance regeneration of seasonal deciduous forests in pastures in central Brazil? Restoration Ecology 15.3: 462471.

Schwinning, S., Weiner, J., 1998. Mechanisms determining the degree of size asymmetry in competition among plants. Oecologia 113.4: 447-455.

Seabloom, E.W., Borer, E.T., Buckley, Y., Cleland, E.E., Davies, K., Firn, J., Harpole, W.S., Hautier, Y., Lind, E., Macdougall, A., Orrock, J.L., Prober, S.M., Adler, P., Alberti, J., Michael Anderson, T., Bakker, J.D., Biederman, L.A., Blumenthal, D., Brown, C.S., Brudvig, L.A., Caldeira, M., Chu, C., Crawley, M.J., Daleo, P., Damschen, E.I., D’Antonio, C.M., Decrappeo, N.M., Dickman, C.R., Du, G., Fay, P.A., Frater, P., Gruner, D.S., Hagenah, N., Hector, A., Helm, A., Hillebrand, H., Hofmockel, K.S., Humphries, H.C., Iribarne, O., Jin, V.L., Kay, A., Kirkman, K.P., Klein, J.A., Knops, J.M.H., La Pierre, K.J., Ladwig, L.M., Lambrinos, J.G., Leakey, A.D.B., Li, Q., Li, W., Mcculley, R., Melbourne, B., Mitchell, C.E., Moore, J.L., Morgan, J., Mortensen, B., O’Halloran, L.R., Pärtel, M., Pascual, J., Pyke, D.A., Risch, A.C., Salguero-Gómez, R., Sankaran, M., Schuetz, M., Simonsen, A., Smith, M., Stevens, C., Sullivan, L., Wardle, G.M., Wolkovich, E.M., Wragg, P.D., Wright, J., Yang, L., 2013. Predicting invasion in grassland ecosystems: is exotic dominance the real embarrassment of richness? Global Change Biology 19.12: 3677-3687.

Seabloom, E.W., Harpole, W.S., Reichman, O.J., Tilman, D., 2003. Invasion, competitive dominance, and resource use by exotic and native California grassland species. Proceedings of the National Academy of Sciences 100.23: 13384-13389.

Seabloom, E.W., Williams, J.W., Slayback, D., Stoms, D.M., H.Viers, J., Dobson, A.P., 2006. Human impacts, plant invasion, and imperiled plant species in California. Ecological Applications 16.4: 1338-1350

Sheley, R.L., Half, M.L., 2006. Enhancing native forb establishment and persistence using a rich seed mixture. Restoration Ecology 14.4: 627-635.

Silva, G.P. et all, 2007. Potencialidade de plantas para revegetação de estéreis e rejeito da mineração de ferro da Mina de Alegria, Mariana-MG. Pesquisa Agropecuária Tropical 36.3: 165-172

Silva, J.F., Fariñas, M.R., Felfili, J.M., Klink, C.A., 2006. Spatial heterogeneity, land use and conservation in the cerrado region of Brazil. Journal of Biogeography 33.3: 536-548.

Silva, L. de C.R., Corrêa, R.S., 2008. Survival and growth of six tree species under four treatments on a mined areain the Brazilian savanna. Revista Árvore 32.4: 731-740.

Silva, L.C.R., Corrêa, R.S., 2010. Evolution of substrate quality of a mined area in the Brazilian savanna after revegetation with Stylosanthes spp. Revista Brasileira de Engenharia Agrícola e Ambiental 14.8: 835-841.

Silva, R.R.P., Oliveira, D.R., Rocha, G.P.E., Vieira, D.L.M., 2015. Direct seeding of 
Brazilian savanna trees: effects of plant cover and fertilization on seedling establishment and growth. Restoration Ecology 23.4: 393-401.

Soares de Andrade, C.M., Garcia, R., Couto, L., Pereira, O.G., de Souza, A.L., 2003. Desempenho de seis gramíneas solteiras ou consorciadas com o Stylosanthes guianensis cv. Mineirão e eucalipto em sistema silvipastoril. Revista Brasileira de Zootecnia 32.6: $1845-1850$.

Starr, C.R., Corrêa, R.S., Filgueiras, T.D.S., Hay, J.D.V., dos Santos, P.F., 2013. Plant colonization in a gravel mine revegetated with Stylosanthes spp. in a Neotropical savanna. Landscape and ecological engineering 9.1: 189-201.

StatSoft, 2011. STATISTICA (data analisys software computer).

Stevens, J.M., Fehmi, J.S., 2011. Early Establishment of a Native Grass Reduces the Competitive Effect of a Non- Native Grass." Restoration Ecology 19.3: 399-406.

Stradic, S. Le, Buisson, E., Fernandes, G.W., 2014. Restoration of Neotropical grasslands degraded by quarrying using hay transfer. Applied vegetation science 17.3: 482-492.

Stylinski, C.D., Allen, E.B., 1999. Lack of native species recovery following severe exotic disturbance in southern Californian shrublands. Journal of Applied Ecology 36.4: 544-554.

Suding, K.N., Goldberg, D.E., 1999. Variation in the effects of vegetation and litter on recruitment across productivity gradients." Journal of Ecology 87.3: 436-449.

Team, R.C., 2014. R: A language and environment for statistical computing. Vienna, Austria: R Foundation for Statistical Computing.

Tecco, P.A., D1, S., Cabido, M., Urcelay, C., 2010. Functional traits of alien plants across contrasting climatic and land- use regimes: do aliens join the locals or try harder than them?." Journal of Ecology 98.1: 17-27.

Tilman, D., 1999. The ecological consequences of changes in biodiversity: a search for general principles." Ecology 80.5: 1455-1474

Tognetti, P.M., Chaneton, E.J., 2012. Invasive exotic grasses and seed arrival limit native species establishment in an old-field grassland succession. Biological Invasions 14.12: 2531-2544

Toh, I., Gillespie, M., Lamb, D., 1999. The Role of Isolated Trees in Facilitating Tree Seedling Recruitment at a Degraded Sub- Tropical Rainforest Site. Restoration ecology 7.3: 288-297.

Toledo, R.E.B. de, Filho, R.V., Pitelli, R.A., Luís, P., Alves, A., Ferraz, C., Alvarenga, S.F., 2003. Períodes de controle de Brachiaria sp e seus reflexos na produtividade de Eucalyptus grandis." Scientia Forestalis/Forest Sciences 221-232.

Vaughn, K.J., Young, T.P., 2015. Short- term priority over exotic annuals increases the initial density and longer- term cover of native perennial grasses. Ecological Applications 25.3: 791-799.

Veldman, J.W., Overbeck, G.E., Negreiros, D., Mahy, G., Le Stradic, S., Fernandes, G.W., Durigan, G., Buisson, E., Putz, F.E., Bond, W.J., 2015. Tyranny of trees in grassy 
biomes. Science 347.6221: 484-485.

Verdú, M., Traveset, A., 2005. Early emergence enhances plant fitness: a phylogenetically controlled meta- analysis. Ecology 86.6: 1385-1394.

Vitor, C.M.T., Fonseca, D.M. da, Melo, L. de M., Fagundes, J.L., Júnior, D. do N., Júnior, J.I.R., Pereira, A.L., 2008. Rendimento e composição química do capimbraquiária introduzido em pastagem degradada de capim-gordura. Revista Brasileira de Zootecnia 37.12: 2107-2114.

Von Gillhaussen, P., Rascher, U., Jablonowski, N.D., Plückers, C., Beierkuhnlein, C., Temperton, V.M., 2014. Priority effects of time of arrival of plant functional groups override sowing interval or density effects: a grassland experiment. PloS one 9.1: e86906.

Wainwright, C.E., Cleland, E.E., 2013. Exotic species display greater germination plasticity and higher germination rates than native species across multiple cues. Biological Invasions 15.10: 2253-2264.

West, D. C., Shugart, H. H., \& Botkin, D. F. 2012 (Eds.). Forest succession: concepts and application. Springer Science \& Business Media.

Wilson, M. V, Clark, D.L., 2001. Controlling invasive Arrhenatherum elatius and promoting native prairie grasses through mowing. Applied Vegetation Science 4.1: $129-138$

Wilson, J.B., 1988. The effect of initial advantage on the course of plant competition. Oikos 19-24.

Young, S.L., Barney, J.N., Kyser, G.B., Jones, T.S., DiTomaso, J.M., 2009. Functionally similar species confer greater resistance to invasion: implications for grassland restoration. Restoration Ecology 17.6: 884-892.

Young, T.P., Petersen, D.A., Clary, J.J., 2005. The ecology of restoration: historical links, emerging issues and unexplored realms. Ecology letters 8.6: 662-673.

Young, T.P., Zefferman, E.P., Vaughn, K.J., Fick, S., 2015. Initial success of native grasses is contingent on multiple interactions among exotic grass competition, temporal priority, rainfall and site effects. AoB Plants 7 plu081.

Zaidan, L.B.P., Carreira, R.C., 2008. Seed germination in Cerrado species. Brazilian Journal of Plant Physiology 20.3: 167-181.

Zavaleta, E.S., Hulvey, K.B., 2004. Realistic species losses disproportionately reduce grassland resistance to biological invaders. Science 306.5699: 1175-1177. 
Anexo 1. Espécies semeadas nos experimentos de semeadura direta nos anos de 2012, 1013 e 2014, nos hábitos de vida arbustos, ervas e árvores, em área de Restauração no Parque Nacional da Chapada dos Veadeiros (PNCV).

\begin{tabular}{|c|c|c|c|}
\hline Nome Científico & Nome comum & Família & Ano \\
\hline \multicolumn{4}{|l|}{ Arbustos } \\
\hline Anacardium humile A. St.-Hil. & Cajuzinho & Anacardiaceae & 2013-2014 \\
\hline Bauhinia cf dumosa Benth. & Pata-de-vaca & Fabaceae & 2013 \\
\hline Vernonanthura polyanthes (Sprengel) Vega \& Dematteis & Assa-peixe & Asteraceae & $2012-2014$ \\
\hline Senna alata (L.) Roxb & Fedegosão & Leguminosae & 2014 \\
\hline Lepdaploa aurea (Mart. ex DC.) H.Rob. & Amargoso & Asteraceae & $2012-2014$ \\
\hline \multicolumn{4}{|l|}{ Subarbustos } \\
\hline Aldama cf. bracteata (Gardner) E.E.Schill. \& Panero & Margarida & Asteraceae & 2013 \\
\hline Stylosanthes capitata Vogel & Estilosantes & Fabaceae & 2012 \\
\hline Stylosanthes macrocephala M.B.Ferreira \& Sousa & Estilosantes & Fabaceae & 2012 \\
\hline \multicolumn{4}{|l|}{ Ervas } \\
\hline Achyrocline satureioides (Lam.) DC. & Macela & Asteraceae & 2013 \\
\hline Axonopus aureus P. Beauv. & Pé de galinha & Poaceae & 2012 \\
\hline Andropogon bicornis $\mathrm{L}$. & Capim vassoura & Poaceae & $2012-2014$ \\
\hline Andropogon fastigiatus $\mathrm{Sw}$. & Andropogon nativo & Poaceae & 2014 \\
\hline Andropogon sp. & Capim mulungu & Poaceae & 2014 \\
\hline Aristida sp. & - & Poaceae & 2012 \\
\hline Aristida gibbosa (Nees) Kunth & Capim rabo de burro & Poaceae & 2013 \\
\hline Aristida riparia Trin. & Rabo-de-raposa & Poaceae & 2014 \\
\hline Axonopus aureus P. Beauv. & Capim pé-de-galinha & Poaceae & 2014 \\
\hline Axonopus barbigerus (Kunth) Hitchc. & Capim colonião & Poaceae & 2014 \\
\hline Echinolaena inflexa (Poir.) Chase & Capim flexinha & Poaceae & 2012 \\
\hline Loudetiopsis chrysothrix (Nees) Conert & Capim brinco de princesa & Poaceae & $2012-2014$ \\
\hline Trachypogon spicatus (L.f.) Kuntze & Capim fiapo & Poaceae & $2012-2014$ \\
\hline Schizachyrium sanguineum (Retz.) Alston & Capim roxo & Poaceae & $2014-2014$ \\
\hline \multicolumn{4}{|l|}{ Arbóreas } \\
\hline Alibertia edulis (Rich.) A.Rich. & Marmelada & Rubiaceae & 2013 \\
\hline
\end{tabular}


Amburana cearensis (Allemão) A.C.Sm.

Anadenanthera colubrina (Vell.) Brenan

Annona crassiflora Mart.

Aspidosperma macrocarpon Mart.

Aspidosperma tomentosum Mart.

Astronium fraxinifolium Schott

Bowdichia virgilioides Kunth

Buchenavia tetraphylla (Aubl.) R.A. Howard

Buchenavia tomentosa Eichler

Cybistax antisyphilitica (Mart.) Mart.

Copaifera langsdorffii Desf.

Cordia alliodora (Ruiz \& Pav.) Oken

Dalbergia miscolobium Benth.

Dimorphandra mollis Benth.

Dipteryx alata Vogel

Emmotum nitens (Benth.) Miers

Enterolobium contortisiliquum (Vell.) Morong

Eremanthus glomerulatus Less.

Enterolobium gummiferum (Mart.) J.F.Macbr.

Eriotheca pubescens (Mart. \& Zucc.) Schott \& Endl.

Eugenia dysenterica (Mart.) DC.

Guazuma ulmifolia Lam.

Hancornia speciosa Gomes

Handroanthus ochraceus (Cham.) Mattos

Hymenaea stignocarpa Hayne

Jacaranda brasiliana (Lam.) Pers.

Magonia pubescens A. St. -Hil.

Myracrodruon urundeuva Allemão

Plathymenia reticulata Benth.

Solanum lycocarpum A. St. -Hil.

Tabebuia aurea (Mart.) Bureau

Imburana
Angico
Araticum
Peroba
Perobinha
Gonçalo-alves
Sucupira preta
Mirindiba
Mirindiba
Ipê verde
Copaíba
Louro amarelo
Dalbergia
Faveiro
Baru
Sôbre
Tamboril
Candeia
Tamboril
Paineira
Cagaita
Mutamba
Mangaba
Ipê Amarelo
Jatobá
Caroba
Tingui
Aroeira
Vinhático
Lobeira
Ipê-caraíba

Fabaceae

$2013-2014$

Fabaceae

$2013-2014$

Annonaceae

2013

Apocynaceae

2013

2013

Apocynaceae

2014

nacardiacea

2013

Combretaceae

2012 - 2013

Combretaceae

2014

Bignoniaceae

2013

Fabaceae

$2013-2014$

Boraginaceae

2014

2013

2013

Fabaceae

Fabaceae

Icacinaceae

Fabaceae

Asteraceae

Fabaceae

Malvaceae

Myrtaceae

Malvaceae

Apocynaceae

Bignoniaceae

Fabaceae

Bignoniaceae

Sapindaceae

Anacardiaceae

Fabaceae

Solanaceae

Bignoniaceae
2012-2013 - 2014

2013

2012-2013

2012 - 2014

2013

2013

2013

2013

2013

2013

2012-2013- 2014

2012 - 2014

2012 - 2014

2012 - 2014

2012

2012 - 2014

2014 
Tachigali vulgaris L.G.Silva \& H.C.Lima

Terminalia argentea Mart.

Terminalia fagifolia Mart.

Palmeira

Syagrus romanzoffiana (Cham.) Glassman
Carvoeiro

Capitão

Capitão do mato
Fabaceae

Combretaceae

Combretaceae

Arecaceae
$2012-2014$

$2012-2014$

2014

Gueroba

2012 